\title{
Novel Secretory Protein Ss-Caf1 of the Plant-Pathogenic Fungus Sclerotinia sclerotiorum Is Required for Host Penetration and Normal Sclerotial Development
}

\author{
Xueqiong Xiao, ${ }^{1,2}$ Jiatao Xie, ${ }^{2}$ Jiasen Cheng, ${ }^{2}$ Guoqing Li, ${ }^{1,2}$ Xianhong $\mathrm{Yi}^{2}{ }^{2}$ Daohong Jiang, ${ }^{1,2}$ \\ and Yanping $\mathrm{Fu}^{2}$ \\ ${ }^{1}$ State Key Laboratory of Agricultural Microbiology, Huazhong Agricultural University, Wuhan 430070, Hubei Province, P. R. \\ China; ${ }^{2}$ The Provincial Key Lab of Plant Pathology of Hubei Province, College of Plant Science and Technology, Huazhong \\ Agricultural University, Wuhan, 430070, Hubei Province, P. R. China
}

Submitted 5 February 2013. Accepted 16 September 2013.

To decipher the mechanism of pathogenicity in Sclerotinia sclerotiorum, a pathogenicity-defective mutant, Sunf-MT6, was isolated from a T-DNA insertional library. Sunf-MT6 could not form compound appressorium and failed to induce lesions on leaves of rapeseed though it could produce more oxalic acid than the wild-type strain. However, it could enter into host tissues via wounds and cause typical necrotic lesions. Furthermore, Sunf-MT6 produced fewer but larger sclerotia than the wild-type strain Sunf-M. A gene, named $S s$-caf1, was disrupted by T-DNA insertion in Sunf-MT6. Gene complementation and knockdown experiments confirmed that the disruption of Ss-caf1 was responsible for the phenotypic changes of Sunf-MT6. Sscaf1 encodes a secretory protein with a putative $\mathrm{Ca}^{2+}$-binding EF-hand motif. High expression levels of Ss-caf1 were observed at an early stage of compound appressorium formation and in immature sclerotia. Expression of Ss-caf1 without signal peptides in Nicotiana benthamiana via Tobacco rattle virus-based vectors elicited cell death. These results suggest that $\mathrm{Ss}$-caf1 plays an important role in compound appressorium formation and sclerotial development of $S$. sclerotiorum. In addition, Ss-Caf1 has the potential to interact with certain host proteins or unknown substances in host cells, resulting in subsequent host cell death.

The ascomycete Sclerotinia sclerotiorum (Lib.) de Bary, also known as white mold or stem rot fungus, is an important plant-pathogenic fungus with worldwide distribution. This pathogen attacks more than 400 plant species, including the model plant Arabidopsis thaliana, and is responsible for significant annual yield loss of many economically important crops, including rapeseed, soybean, carrot, and sunflower (Boland

Nucleotide sequence data for the Ss-cafl gene is available under ID number 5492623.

Corresponding author: Y. Fu; Telephone: +86-27-87280487; Fax: +86-2787280487; E-mail: yanpingfu@mail.hzau.edu.cn

* The $\boldsymbol{e}$-Xtra logo stands for "electronic extra" and indicates that ten supplementary figures and one supplementary table are published online and that Figures 3, 4, 5, and 7 appear in color online.

(C) 2014 The American Phytopathological Society and Hall 1994; Bolton et al. 2006). S. sclerotiorum can produce numerous sclerotia, which are the long-term resting structures, on diseased plants (Bolton et al. 2006). This resting structure is able to resist adverse conditions and can survive in soil for more than 8 years (Adams and Ayers 1979). Under suitable environmental conditions, sclerotia can directly germinate to initiate new infections or germinate carpogenically to release huge numbers of ascospores, which are the principal source of primary inoculum. Therefore, blocking sclerotial development might be an effective method to control Sclerotinia diseases. Although many genes or nutritional factors related to sclerotial development have been identified (Chen and Dickman 2005; Chen et al. 2004; Erental et al. 2008; Harel et al. 2005, 2006; Li and Rollins 2009, 2010; Rollins 2003; Yu et al. 2012; Zhu et al. 2013), molecular mechanisms involved in sclerotial development remain to be elucidated.

As a typical necrotrophic pathogen, S. sclerotiorum must penetrate and kill its host to occupy dead cells and absorb nutrient sources from the dead tissues. In spite of the plant cuticle and cell wall barriers against invasion by the pathogen, $S$. sclerotiorum has developed effective means to breach these defense mechanisms. Mechanistically, these include secretion of oxalic acid (Cessna et al. 2000; Favaron et al. 2004; Godoy et al. 1990; Guimarães and Stotz 2004; Kabbage et al. 2013; Kim et al. 2008; Magro et al. 1984; Williams et al. 2011) and cellwall-degrading enzymes (CWDE) (Lumsden 1969; Martel et al. 1996; Poussereau et al. 2001; Riou et al. 1991; Yajima et al. 2009; Zuppini et al. 2005). In addition to these key pathogenicity factors, many other factors involved in development and pathogenesis of $S$. sclerotiorum have been identified, and some of them have been characterized at the molecular level (Erental et al. 2007; Harel et al. 2006; Jurick and Rollins 2007; Kim et al. 2011; Li et al. 2012; Liberti et al. 2013; Rollins 2003; Xu and Chen 2013). For example, an integrin-like protein of $S$. sclerotiorum is likely to work, at early stages of infection, as an effector to suppress jasmonic/ethylene (JA/ET) signal pathway-mediated resistance in the host (Zhu et al. 2013).

Formation of appressoria is an innovation that some fungal phytopathogens have evolved to penetrate their hosts. Previously reported ultrastructural and cytochemical studies showed that, prior to penetration, the tips of $S$. sclerotiorum hyphae become swollen and extensively branched, and then form modified multicellular, melanin-rich hyphal structures, which are called compound appressoria, and are also known as infection cushions 
(Huang et al. 2008; Jamaux et al. 1995; Lumsden and Dow 1973; Tariq and Jeffries 1984). Additionally, compound appressoria are also observed when $S$. sclerotiorum is cultured on abiotic surfaces, such as aluminum foil, glass cover slips, or the sides of plastic petri dishes (Tariq and Jeffries 1984). Sticky mucilage covering the surface of compound appressoria might contribute to increase the adhesion of $S$. sclerotiorum to the plant surface and facilitate effective penetration into the host tissues (Tariq and Jeffries 1984). Moreover, the plant cuticle may be perforated by thin penetration pegs that originate from flattened hyphae of the compound appressorium, and some infection holes may be observed on the surface of hosts after the compound appressorium is removed (Huang et al. 2008). In addition, compound appressoria seem to exert a mechanical force and are presumed to secrete enzymes and toxins (Huang et al. 2008; Jamaux et al. 1995). However, the molecular mechanism underpinning compound appressorial formation and its detailed functions in $S$. sclerotiorum are still largely uncharacterized.

Because adequate disease resistance to $S$. sclerotiorum is not commercially available, management of diseases caused by $S$. sclerotiorum relies on the application of fungicides. However, fungicide sprays often exert an associated risk of developing fungicide-resistant fungal isolates (Gossen et al. 2001) and may pose potential harmful effects on the environment (Komárek et al. 2010). Elucidating the mechanisms of pathogenicity and sclerotial development will help facilitate the development of new control strategies of Sclerotinia diseases. To this end, we used an Agrobacterium tumefaciens-mediated transformation (ATMT) method to construct a T-DNA insertional mutant library based on a wild-type strain Sunf-M of $S$. sclerotiorum. All of the T-DNA insertional mutants were screened for pathogenicity on Arabidopsis thaliana, and resulting pathogenicity-defective mutants were identified. An interesting mutant, Sunf-MT6, defective in pathogenicity and sclerotial development, was obtained from the insertional library and the $S$. sclerotiorum compound appressorium formation related gene 1 ( $S s$-cafl), which was disrupted by T-DNA insertion, was identified. Thus, the aim of the present research was to investigate the biological roles of the novel gene Ss-cafl in pathogenicity and sclerotial development of S. sclerotiorum.

\section{RESULTS}

\section{T-DNA insertion in Sunf-MT6 disrupted a gene that is an ortholog of yeast ssp120 gene.}

A T-DNA insertional mutant library of $S$. sclerotiorum with approximately 800 transformants was constructed by ATMT. To identify genes involved in the pathogenicity of S. sclerotiorum, the virulence assay of all transformants of the mutant library was performed on A. thaliana. The lesions of A. thaliana were evaluated at 4 days postinoculation (dpi). In the present study, a mutant Sunf-MT6, lacking pathogenicity, was uncovered. $S s$-cafl, which in Sunf-MT6 was disrupted by the T-DNA insertion, was identified and characterized. The T-DNA flanking sequence was amplified by the high-efficiency thermal asymmetric interlaced polymerase chain reaction (hiTail-PCR) technique (Liu and Chen 2007), and a schematic representation of T-DNA insertion in Sunf-MT6 is depicted in Figure 1A. The T-DNA insertion site in mutant Sunf-MT6 was found in the third exon of the hypothetical gene SS1G_02486 (Broad Institute), 644 bp downstream (between nucleotides $\mathrm{A}^{644}$ and $\mathrm{C}^{645}$ ) from the start codon site. The T-DNA insertion event was further confirmed by PCR and reverse-transcription (RT)-PCR with primers complementary to the T-DNA flanking sequence and the T-DNA border, and amplicons of the expected sizes were obtained (Fig. 1B). In addition, RT-PCR analysis con- firmed the absence of transcription of SS1G_02486 in SunfMT6 (Fig. 1B). Southern hybridization analysis indicated that only a single T-DNA insertion exists in the mutant (Fig. 1C). In addition, the size of the hygromycin resistance gene ( $h p h$ )hybriding band $(3,475 \mathrm{bp})$ was consistent with that of the SacI fragment carrying the T-DNA-tagged gene.

SS1G_02486 is located on chromosome 4, and the protein (accession number XP_001596266) encoded shares 34\% identity $(\mathrm{E}$ value $=2 \mathrm{e}-21)$ with secreted protein 120 (Ssp120, AAA35068) of Saccharomyces cerevisiae (Sidhu et al. 1991). Based on the data described below, we designated the T-DNA tagged gene to be $S s$-cafl.

Ss-cafl contains a 776-bp open reading frame (ORF) with three exons $(132,320$, and $169 \mathrm{bp}$ in length), which were confirmed by RT-PCR and sequencing (data not shown). This ORF was predicted to encode a protein of 206 amino acids that was rich in the amino acids D (11.7\% of total) and E (10.2\%). Phylogenetic analysis indicated that orthologs of Ss-Caf1 are widely present in ascomycetes and basidiomycetes, including some important plant pathogens, such as Botryotinia fuckeliana (XP_001556350), Gibberella zeae (XP_381642), and Magnaporthe oryzae (XP_361469) (Fig. 1D). Sequence alignment of Ss-Caf1 with its orthologs revealed that these sequences are well conserved in length and amino acid composition among filamentous ascomycete, and $\mathrm{H}$ amino acid residues are conserved among all mature protein sequences (Supplementary Fig. S1).

\section{Ss-Caf1 is a secreted protein}

with a putative $\mathrm{Ca}^{2+}$-binding $\mathrm{EF}$-hand motif.

Ss-Caf1 was predicted, using the program TMHMM server version 2.0, to have an extracellular and non-membrane location (Supplementary Fig. S2A). Two signal peptide prediction methods, SignalP-NN server version 3.0 (based on neural networks) and SignalP-HMM server version 3.0 (based on hidden Markov models) (Bendtsen et al. 2004), were used to predict a signal peptide and the cleavage site. A signal peptide was predicted at the $\mathrm{N}$-terminal region. The predicted cleavage site was between amino acid position $\mathrm{A}^{25}$ and $\mathrm{H}^{26}$, generating a small mature protein with a theoretical molecular weight of $21.29 \mathrm{kDa}$ and an isoelectric point of 4.72 .

To identify the subcellular location of Ss-Caf1, immunoelectron microscopy with anti-Ss-Caf1 polyclonal antibodies was used. Gold particles were not detected in the cells treated with pre-immune serum (Fig. 2A1, B1, and C1). Immunogold labeling of ultrathin sections with anti-Ss-Caf1 polyclonal antibodies demonstrated that gold particles primarily accumulated in the cytoplasm and cell walls of Sclerotinia sclerotiorum, with some particles located extracellularly during vegetative growth and sclerotial development (Fig. 2A2, B2, and C2), but none were inside the nucleus (Fig. 2A3). Moreover, Ss-Caf1 was detected in fermentation broth of the wild-type strain but absent in that of the mutant Sunf-MT6 (Fig. 2D).

A Scanprosite analysis of protein sequence for motifs and functional sites revealed that an EF-hand $\mathrm{Ca}^{2+}$-binding motif was predicted at amino acid positions $\mathrm{K}^{92}$ to $\mathrm{L}^{127}$ (score = 9.464), with a potential $\mathrm{Ca}^{2+}$-binding loop at position $\mathrm{D}^{105}$ to $\mathrm{E}^{116}\left(\mathrm{D}^{105} \mathrm{SNNDGVVEKEE}{ }^{116}\right)$. The $\mathrm{Ca}^{2+}$-binding loop usually consists of 12 residues with a pentagonal bipyramidal pattern, and the calcium chelating residues are designated as follows: 1(+X), 3(+Y), 5(+Z), 7(-Y), 9(-X), 12(-Z) (Gifford et al. 2007). The most common amino acids at each position of these 12 residues (Gifford et al. 2007) are shown in Figure 3A. The $\mathrm{Ca}^{2+}$-binding loop sequence of nucleobindin, a $\mathrm{Ca}^{2+}$-binding protein with two typical EF-hand motifs (de Alba and Tjandra 2004), was selected as a reference sequence. Similar to nucleobindin, the $\mathrm{Ca}^{2+}$-binding loop sequence of Ss-Caf1 also comprises 12 conserved residues (Fig. 3A). Moreover, the three- 


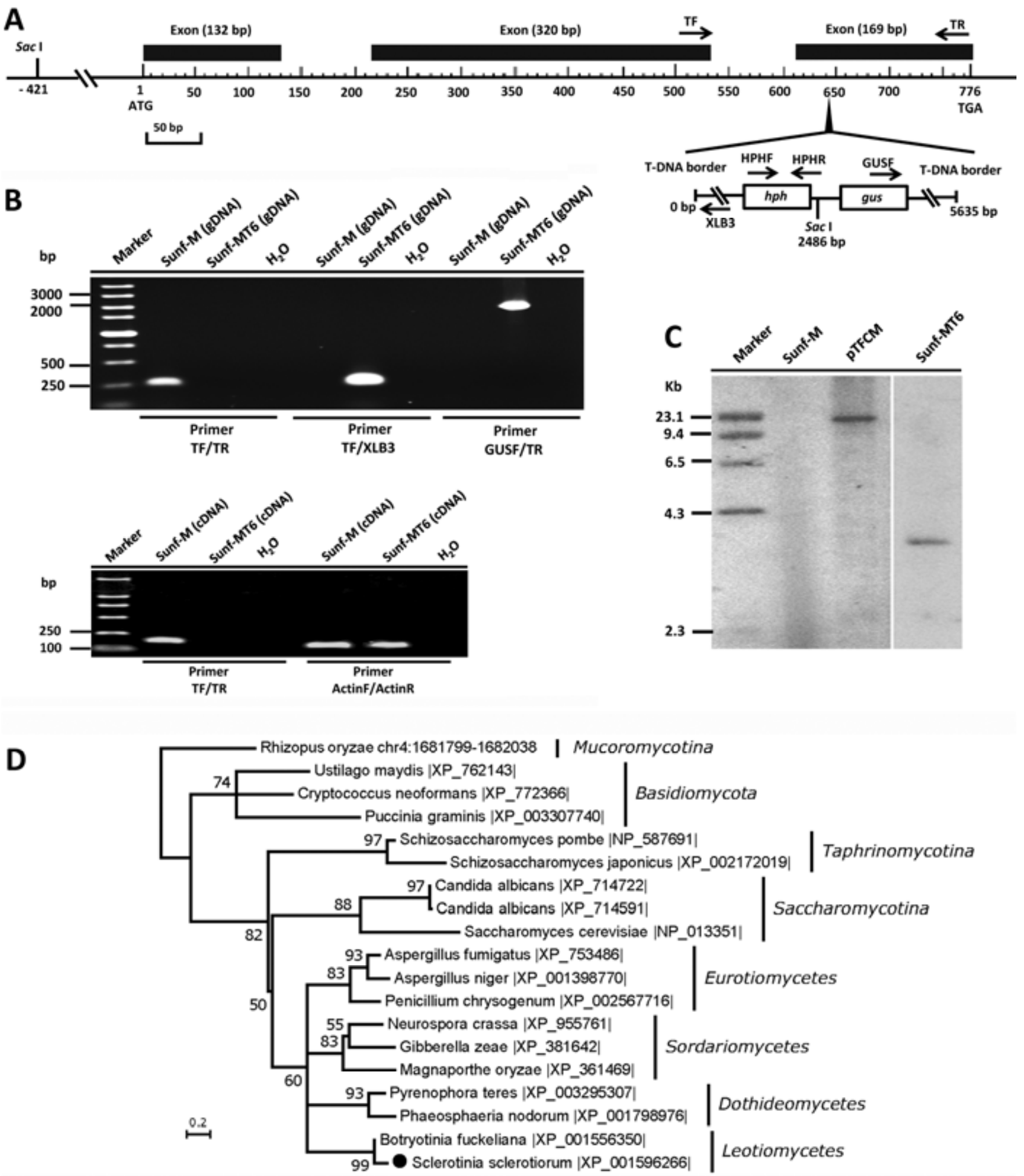

Fig. 1. Analysis of T-DNA insertion event in the mutant Sunf-MT6 of Sclerotinia sclerotiorum. A, Schematic representation of the location of T-DNA insertion in Ss-cafl. Three exons are symbolized by black bars. ATG denotes the start codon and TGA denotes the stop codon. The black triangle refers to the T-DNA insertion at the third exon. The scale bar corresponds to a nucleotide length of $50 \mathrm{bp}$. Locations of primers TF, TR, XLB3, HPHF, HPHR, and GUSF are shown above and below the arrowheads. B, Polymerase chain reaction (PCR) amplification fragments from genomic DNA to confirm the T-DNA insertion site with primer pairs TF/XLB3, GUSF/TR, and TF/TR (upper panel), and reverse-transcription PCR amplification fragments of Ss-caf1 from cDNA with primer pair TF/TR (lower panel). The actin amplification generated by PCR amplification of cDNA with primer pair ActinF/ActinR served as an internal control; sizes of molecular mass standards (DL5000 Ladder Marker; Takara) are indicated to the left of each panel. C, Southern blot analysis of the T-DNA insertion site in the mutant Sunf-MT6. Genomic DNA of mutant Sunf-MT6, the wild-type strain Sunf-M (negative control), and plasmid pTFCM (positive control) were digested completely with $\mathrm{SacI}$ and a fragment of the hygromycin resistance gene ( $h p h)$ labeled with $\alpha{ }^{32} \mathrm{P}$ was used as a probe. Sizes of molecular mass standards ( $\lambda$-HindIII digest Ladder Marker; Takara) are indicated to the left of the panel. D, Unrooted neighbor-joining tree of protein Ss-Caf1 was constructed with its homologs from other fungi; bootstrap values (\%) obtained with 1,000 replicates are indicated on branches and branch lengths correspond to genetic distance; a scale bar at the lower left corresponds to a genetic distance of 0.2. 
dimensional structure of Ss-Caf1 was predicted with Phyre2 using the principles and techniques of homology modeling (Kelley and Sternberg 2009). Nucleobindin (Protein Data Bank code d1snlA) was selected as the template to construct the model of Ss-Caf1, and 83 residues were modeled with 99.6\% confidence (Fig. 3B). The three-dimensional structure of Ss-Caf1 was similar to that of the $\mathrm{Ca}^{2+}$-binding protein nucleobindin (Fig. 3C).

\section{Sunf-MT6 is a sclerotial-development-defective mutant.}

Mutant Sunf-MT6 grew on potato dextrose agar (PDA) at a rate of $1.4 \mathrm{~cm} /$ day, which was $12.5 \%$ slower than the wild-type strain Sunf-M (1.6 cm/day). At the same time, Sunf-MT6 colonies produced less melanin than those of the wild-type strain Sunf-M (data not shown). Furthermore, only after 15 days on PDA did the Sunf-MT6 mutant began to produce sclerotia (data not shown). By contrast, the wild-type strain initiated sclerotial production by 3 to 4 days under the same conditions, and mature sclerotia were usually observed by 7 to 8 days of incubation (data not shown). Even after 30 days of development, the melanization of sclerotia produced by Sunf-MT6 was not complete (Fig. 4A). The diameter of sclerotia of Sunf-
MT6 was nearly two times larger than that of Sunf-M (Fig. 4A). The sclerotia of Sunf-MT6 floated in water whereas those of Sunf-M sank (Fig. 4B), implying that the sclerotial density of Sunf-MT6 was lower than Sunf-M. Strains were cultured on PDA for 30 days and sclerotia were collected to observe the ultrastructure by transmission electron microscopy (TEM). The results showed that Sunf-MT6 had a looser interior texture than that of the wild-type strain, and some cells had relatively large vacuoles (Fig. 4C). The number of sclerotia produced by Sunf-MT6 (approximately six sclerotia per 9-cm-diameter plate) was $81 \%$ less than that of Sunf-M (approximately 32 sclerotia/plate) (Fig. 4D, left panel). In addition, the fresh sclerotial weight of Sunf-MT6 cultures was higher than that of the wild type but dry sclerotial weight of Sunf-MT6 cultures was lower (Fig. 4D, right panel). The same results were obtained when strains were cultured on autoclaved carrot roots, which allowed abundant sclerotial formation (data not shown). Additionally, sclerotia of Sunf-MT6 failed to germinate and form apothecia, whereas the wild-type strain produced apothecia and released ascospores normally (data not shown).

The different sclerotial developmental stages of the wildtype strain Sunf-M grown on PDA are displayed in Figure 5A.
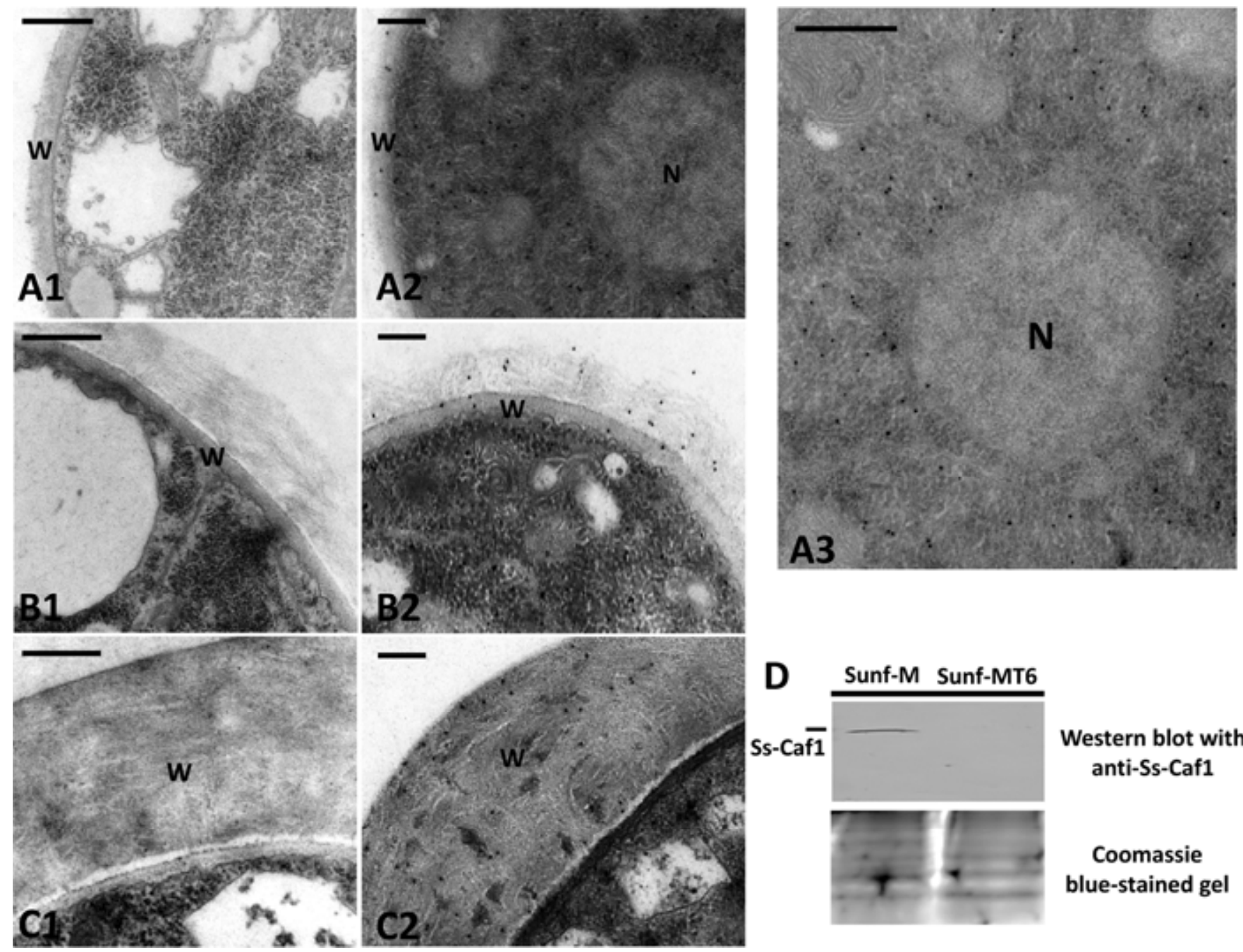

Western blot with anti-Ss-Caf1

Fig. 2. Immunogold subcellular localization of Ss-Caf1 in Sclerotinia sclerotiorum. The control reaction conducted by incubating with pre-immune serum shows no gold traces in A1, hyphae; B1, sclerotial initial stage; or C1, mature sclerotium. Immunogold labeling of ultrathin sections with anti-Ss-Caf1 polyclonal antibodies shows the gold particles in the cell wall and cytoplasm of A2, hyphae during vegetative growth (on potato dextrose agar after 1 day); B2, initial stage of sclerotia (cultured for 4 days); and C2, mature sclerotium (cultured for 7 days) but located out of the nucleus. A3, Partial enlarged image of A2. $\mathrm{W}=$ cell wall and $\mathrm{N}=$ nucleus. Scale bar $=0.5 \mu \mathrm{m}$. D, Detection of protein Ss-Caf1 in fermentation broth of the wild-type strain and mutant (cultured in potato dextrose broth with shaking for 3 days) by Western blot analysis with anti-Ss-Caf1 polyclonal antibodies (upper panel), and the Coomassie bluestained gel of the total protein extraction from fermentation broth (lower panel). 
Western blot analysis with anti-Ss-Caf1 polyclonal antibodies suggested that Ss-Caf1 accumulated to higher levels during early stages of sclerotial development when immature, nonmelanized sclerotia were formed, and to lower levels during vegetative hyphal growth and sclerotial initiation and maturation (Fig. 5B).

\section{Sunf-MT6 is a pathogenicity-defective mutant.}

The pathogenicity assay of mutant Sunf-MT6 on intact leaves of A. thaliana and rapeseed revealed that mutant Sunf-MT6 had lost its capability to infect its host and, hence, Sunf-MT6 was a pathogenicity-deficient mutant (Fig. 6A). Because S. scleroti- orum has a broad host range, the pathogenicity of this mutant was also tested on other hosts, and the results showed that Sunf-M but not Sunf-MT6 successfully infected detached leaves of hosts, including pak choi cabbage, hot pepper, tomato, cucumber, soybean, and the stems of rapeseed (Supplementary Fig. S3). However, after leaves were wounded with a needle, mutant Sunf-MT6 could infect hosts and induce lesions, although the lesions were much smaller than those caused by the wild type (Fig. 6A; Supplementary Fig. S4). These results suggest that, although the mutant Sunf-MT6 was unable to penetrate the intact cuticle of host plants, it can extend into host tissues and induce typical lesions once the cuticle barriers are bypassed.

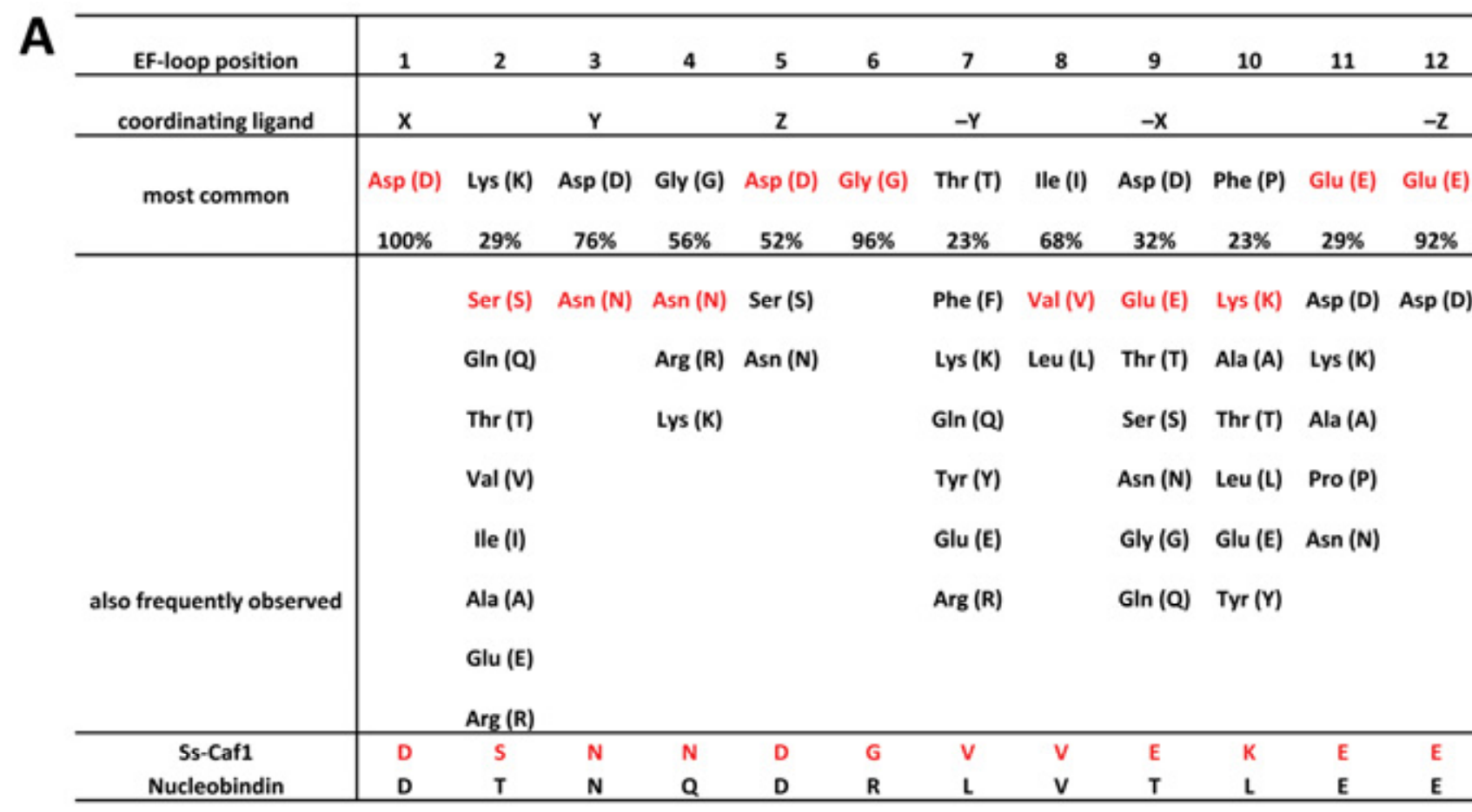

B

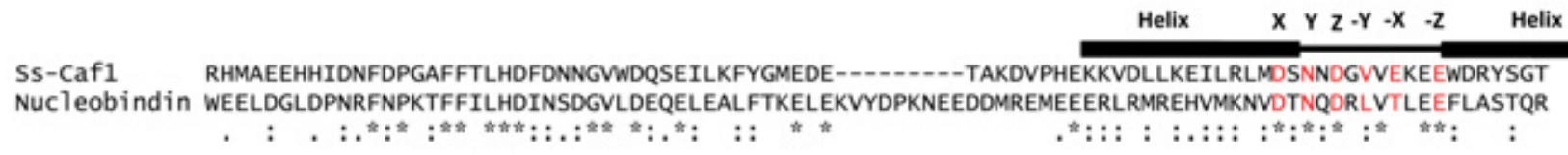

C
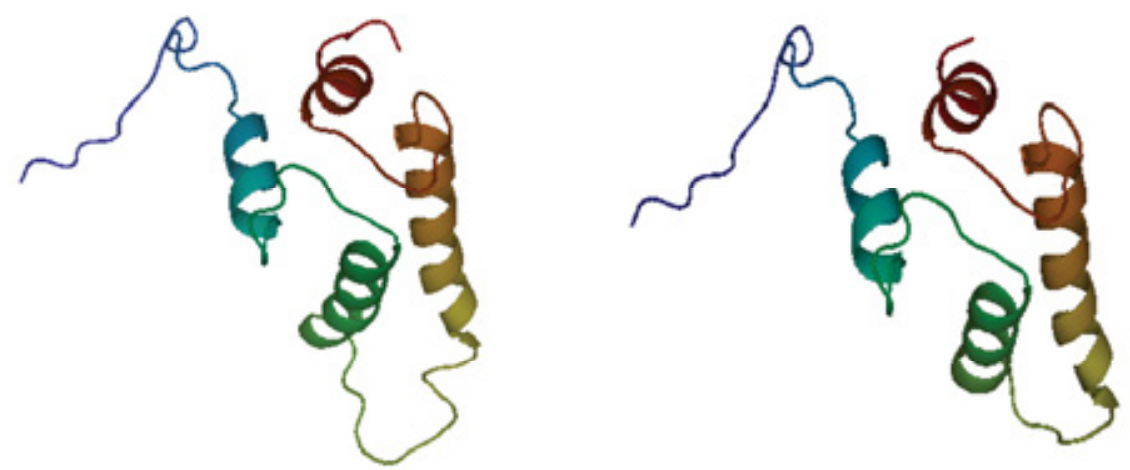

Ss-Caf1

Nucleobindin

Fig. 3. Prediction of EF-hand motif in Ss-Caf1. A, The most common and frequently observed amino acids in EF-hand $\mathrm{Ca}^{2+}$-binding loops at $\mathrm{X}, \mathrm{Y}, \mathrm{Z},-\mathrm{Y},-\mathrm{X}$, and $-\mathrm{Z}$ positions (\% represents the amino acids similarity), with the $\mathrm{Ca}^{2+}$-binding loop acid sequences of Ss-Caf1 and nucleobindin (black) shown; the amino acids of Ss-Caf1 that are similar to the preferred amino acids appear in gray. B, Sequence alignment of the EF-hand motif from Ss-Caf1 and nucleobindin. $\mathrm{Ca}^{2+}$-binding loop at $\mathrm{X}, \mathrm{Y}, \mathrm{Z},-\mathrm{Y},-\mathrm{X}$, and $-\mathrm{Z}$ positions are labeled in gray; the bold black bars indicate the helix of EF-hand motif. Identical residues are indicated by asterisks; conserved and semiconserved amino acid residues are indicated by colons and dots, respectively. $\mathbf{C}$, Comparison of the three-dimensional (3D) models of Ss-Caf1 protein and nucleobindin. The 3D structural models were generated with Phyre 2 program. 
Sunf-MT6 produces oxalic acid and plant CWDE.

The yellow color observed when Sunf-MT6 grew on medium containing bromophenol blue (Fig. 6B) suggests that Sunf-MT6 could secrete acid. Quantitative assays of 3-day-old cultures grown in potato dextrose broth (PDB) showed that the $\mathrm{pH}$ of Sunf-MT6 ( $\mathrm{pH}$ 2.2) was significantly lower than that of Sunf-M (pH 3.1) (Fig. 6C). Furthermore, the oxalic acid yield of Sunf-MT6 (239 mg/g of dry mycelia) was significantly higher than that of the wild-type strain $(63 \mathrm{mg} / \mathrm{g}$ ) (Fig. 6D). The production of CWDE was evaluated on media containing various substrates or indicators. The results showed that SunfMT6 could secrete CWDE, including pectinases, cellulases, proteases, and amylases (Supplementary Figure S5).
Sunf-MT6 is severely inhibited by stress conditions.

The sensitivity of strains to different stress conditions was evaluated. The growth rate of the mutant Sunf-MT6 was slightly slower than the wild type on PDA. High concentrations of calcium ions inhibited the hyphal growth of both the wild-type strain and the Ss-cafl-disrupted mutant; however, the mutant was more sensitive to $\mathrm{Ca}^{2+}$ than the wild-type strain (Fig. 7A and B). In addition, the mutant Sunf-MT6 did not grow well under stress conditions, such as on media containing high concentrations of salt $\left(\mathrm{NaCl}, \mathrm{KCl}\right.$, or $\mathrm{MgCl}_{2}$ ), sugar alcohols (sorbitol or mannitol), sucrose, and antibiotic G418 (Fig. 7C and D), suggesting that the mutant Sunf-MT6 is more severely inhibited by a broad range of stress conditions than the wild type.
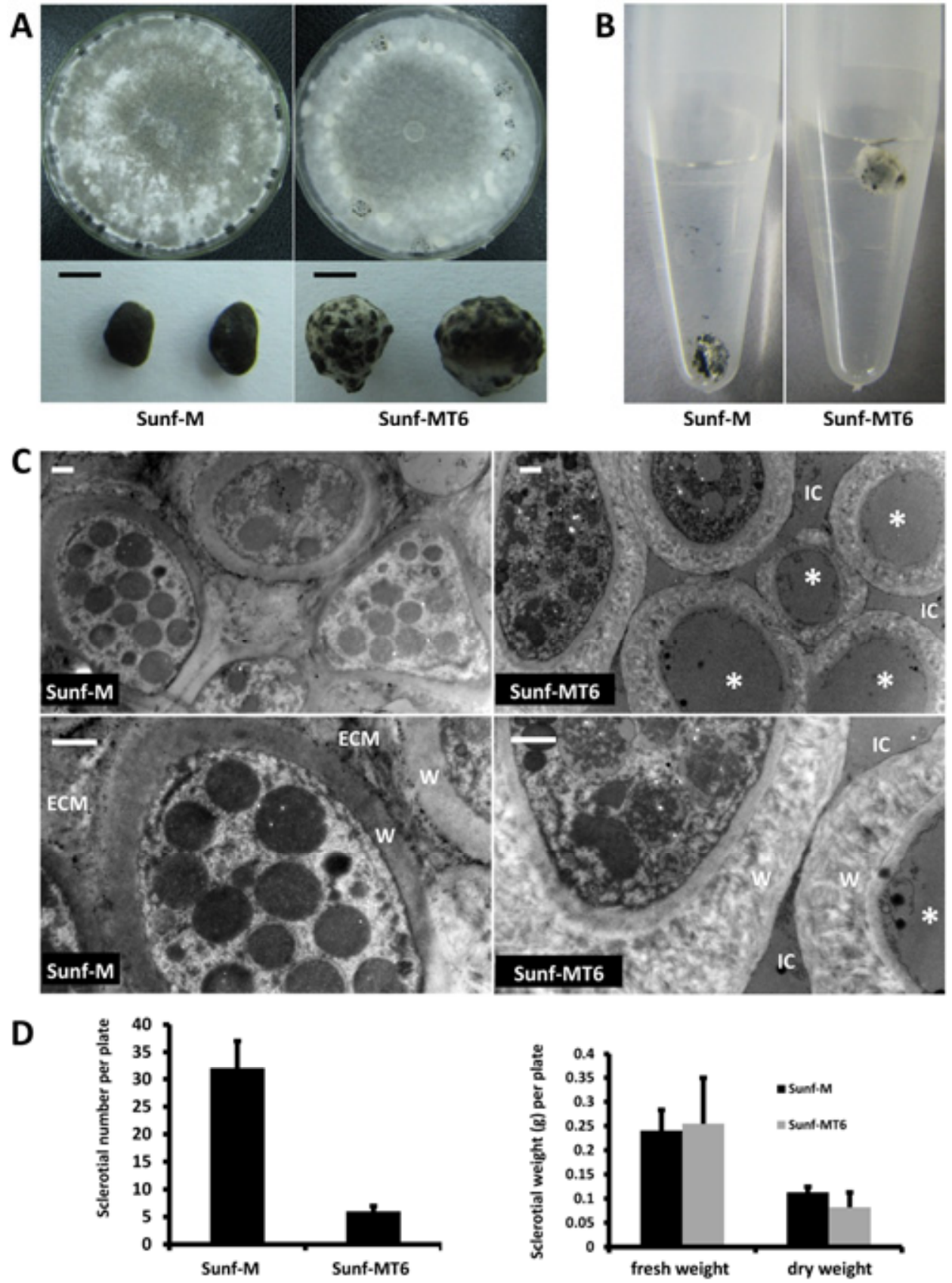

Fig. 4. Colony morphology and sclerotial formation of T-DNA insertional mutant Sunf-MT6. Sunf-MT6 was cultured on potato dextrose agar (PDA) for 30 days at $20^{\circ} \mathrm{C}$. The wild-type strain Sunf-M was used as a control. A, Colony morphology developed on PDA (upper panel) and sclerotial morphology (lower panel), scale bar $=2 \mathrm{~mm}$. B, Comparison of the sclerotial density of Sunf-M and Sunf-MT6 in water. C, Ultrastructure of sclerotia observed by transmission electron microscopy. The lower panels are partial enlarged images of the upper panels. Asterisks indicate the cells with a large central vacuole; W = cell wall, $\mathrm{ECM}=$ extracellular matrix, and IC = intercellular space. Scale bar $=0.5 \mathrm{~mm}$. D, Sclerotial number (left panel) and sclerotial fresh weight and dry weight (right panel) of strains grown on PDA. Values are the averages of five independent trials. Bars indicate standard error. 
Disruption of Ss-caf1 is responsible for phenotypic changes of mutant Sunf-MT6.

To determine whether phenotypes of the mutant Sunf-MT6 were exclusively produced by the disruption of $S s$-cafl, an intact copy of Ss-cafl was introduced into mutant Sunf-MT6 with the complementation vector pT6COM (Supplementary Fig. S6A). Thirteen candidate complemented transformants were obtained, among which eight showed restored pathogenicity to rapeseed (data not shown). The $S s$-cafl-complemented transformants were confirmed with RT-PCR amplification. The proposition that $S s$-cafl is involved in sclerotial development and pathogenicity was further confirmed by RNA-interferencemeditated gene silencing. A silencing vector, pT6RN, was constructed to knockdown expression level of Ss-cafl in the wildtype strain (Supplementary Fig. S7A). In all, 47 candidates were obtained, among which 19 showed similar colony morphology to the mutant Sunf-MT6 (data not shown); the expression level of Ss-cafl in transformants T6RN26 and T6RN32 was significantly suppressed. The phenotype of Ss-cafl-complemented transformants T6COM14 resembled that of the wild-type strain (Fig. 8; Supplementary Fig. S8), with restoration of pathogenicity and sclerotial production; the Ss-caflsilenced transformants T6RN26 and T6RN32 displayed a dramatic reduction in pathogenicity to rapeseed (Fig. 8). These results suggest that the disruption of $S s$-cafl is involved in sclerotial development and pathogenicity of S. sclerotiorum.

\section{Ss-cafl is associated}

with compound appressorium formation.

The infection process by the mutant Sunf-MT6 was investigated to determine the reason for defective pathogenicity. Sunf-M and Sunf-MT6 were inoculated onto intact leaves of $A$. thaliana Col-0, and the infection process was observed by scanning electron microscopy (SEM). When inoculated with a mycelial disc of Sunf-M, compound appressoria initials were found within $4 \mathrm{~h}$ postinoculation (hpi) on the leaf surface (Fig. 9A). Consistent with previous studies, which showed that the surface of compound appressoria were covered with sticky mucilage (Huang et al. 2008), compound appressoria of Sunf-M were also covered with mucilage by 12 hpi (Fig. 9A). Moreover, some compound appressoria were observed penetrating into the plant cuticle (Fig. 9B). Penetration was followed by the formation of secondary compound appressoria from hyphae that extended on leaves, and hyphal extension from compound appressoria formed a dense network (data not shown). At 16 hpi, hyphae were observed under the epidermal tissues and lesions were visible on the leaves (data not shown). In contrast to Sunf-M, SunfMT6 was incapable of forming compound appressoria on the leaf surface (Fig. 9C), and could not cause lesions even after 4 days (Fig. 6). Similar results were obtained when Sunf-M and Sunf-MT6 were inoculated onto rapeseed leaves and observed by light microscopy (Supplementary Fig. S9). In addition, complemented transformants could form compound appressoria similar to those of the wild-type strain, whereas hyphal tips of Ss-cafl-silenced transformants swelled and bifurcated to form simple infection structures but did not develop into abundant compound appressoria (data not shown).

Because Sunf-MT6 can infect wounded plants, the infection processes of $S$. sclerotiorum on wounded plants were observed microscopically. It is interesting to note that no compound appressoria were observed when both the wild-type strain and mutant Sunf-MT6 were inoculated onto wounded leaves of either Arabidopsis or rapeseed (Fig. 9D). The hyphae of both strains grew toward the wounds and directly penetrated into Arabidopsis leaves through the wounds (Fig. 9D). Similar results were observed when the strains were inoculated on the wounded leaves of rapeseed.

Ss-cafl expression was evaluated via quantitative PCR (qPCR) during the infection process on A. thaliana Col-0 or vegetative growth on cellophane placed on PDA. The results demonstrated that $S$-cafl was expressed at a high level over the time course from 4 to 12 hpi onto leaves of Arabidopsis, and that the highest expression was detected at 4 hpi, during the initial stages of compound appressorium formation (Fig.

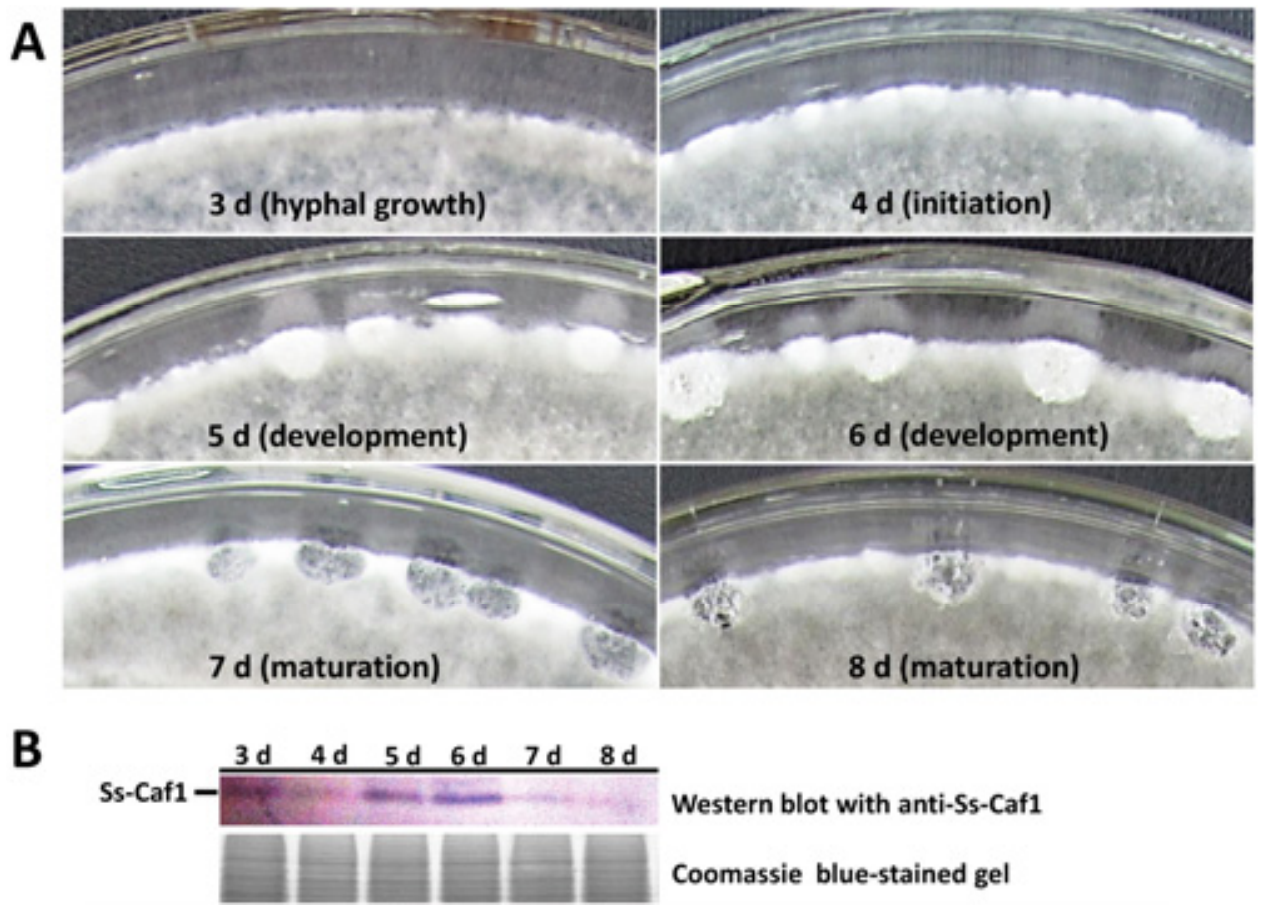

Fig. 5. Analysis of Ss-Caf1 accumulation during different developmental stages of the wild-type strain Sunf-M growing on potato dextrose agar (PDA). A, Time course of sclerotial development of the wild-type strain Sunf-M on PDA at $20^{\circ} \mathrm{C}$. B, Western blot probed with anti-Ss-Caf1 polyclonal antibodies (upper panel) and Coomassie blue-stained gel of total protein extracts from the fungal mycelia (lower panel), showing high accumulation at the sclerotial development stage. 
9E), whereas the transcript accumulation was much less during vegetative growth on PDA (Fig. 9E).

\section{Expression of Ss-caf1 \\ in Nicotiana benthamiana induces host cell death.}

As a secretory protein, Ss-Caf1 has the potential to enter plant cells during the early infection stage. Thus, the expression of Ss-cafl in Nicotiana benthamiana was tested to confirm the function of Ss-cafl. The Tobacco rattle virus (TRV)-based expression vectors were used to express full-length Ss-cafl or an incomplete gene (lacking the signal peptide sequence) in $N$. benthamiana. The leaves of $N$. benthamiana were co-infiltrated with cultures of recombinant Agrobacterium strains containing expression vectors of pTRV1 with pTRV2N-T6 (fulllength gene), either TRV2N-T6 $\Delta$ SP (without signal peptide [SP]) or empty vector pTRV2N. In five independent experiments, no significant plant reactions were observed when infiltrated with pTRV2N-T6 or pTRV2N (Fig. 10A), whereas necrosis in $N$. benthamiana leaves was observed at 5 days postinfiltration or inoculation (dpi) with the Agrobacterium strain carrying pTRV2N-T6 $\Delta$ SP (data not shown). Furthermore, the necrosis could extend along with viral spread throughout the whole plant, and more necrotic lesions appeared on leaves and stems at $10 \mathrm{dpi}$, with strong responses by $N$. benthamiana at $17 \mathrm{dpi}$ (Fig. 10A). Five repeated experiments (five plants of $N$. benthamiana per treatment in each experiment) showed $100 \%$ necrosis on the whole plants for expression of the $S s$-cafl gene lacking a signal peptide and $0 \%$ for all other treatments. The results of RT-PCR amplification confirmed that Ss-cafl was successfully expressed in N. benthamiana (Fig. 10B).

\section{DISCUSSION}

S. sclerotiorum is a model necrotrophic fungal pathogen; it produces oxalic acid and CWDE to kill plant cells, and subsequently grows in them. Oxalic acid is a key pathogenicity factor, and $S$. sclerotiorum may regulate the secretion of oxalic acid. Our results suggest that the pathogenicity-defective mutant Sunf-MT6 was capable of secreting oxalic acid and CWDE during the course of vegetative growth, while the oxalic acid production was approximately four times higher than that of the wild-type strain. Ss-cafl, a novel gene, was determined to be responsible for the phenotype of the Suf-MT6 mutant. The functions of Ss-cafl in host penetration and sclerotial development were characterized.

Although orthologs of Ss-Caf1 are widely present in ascomycetes and basidiomycetes, except for the ortholog Ssp120 in yeast, the functions of all other orthologs are not clear. In $S$. cerevisiae, Ssp120 acted as a cargo-specific adaptor to interact with Emp46 and Emp47, which facilitate secretion by sorting cargo proteins into endoplasmic-reticulum-derived COPIIcoated vesicles, and participated in Golgi to endoplasmic reticulum recycling (Babu et al. 2012). Green fluorescent proteintagged Ssp120 in S. cerevisiae localized to early Golgi (Babu et al. 2012), while SsP120 of Kluyveromyces lactis could be detected in spent fermentation medium (Madinger et al. 2009), which implies that Ssp120 could be secreted out of cell wall into the medium. Ss-Caf1 contains a signal peptide, suggesting that it is likely a secreted protein. This secretion property was confirmed by both immunoelectron microscopy and Western blot analysis of culture filtrates.

Bioinformatics analyses predicted that Ss-Caf1 possesses a putative EF-hand motif. Proteins with EF-hand motifs have a function in binding $\mathrm{Ca}^{2+}$ (Lewit-Bentley and Réty 2000) and are the major proteins to do so (Gifford et al. 2007). EF-hand motifs usually occur in pairs but a few $\mathrm{Ca}^{2+}$-binding proteins have been reported to contain only a single motif (Reddy et al. 2004). EFhand proteins can function as signaling (also called $\mathrm{Ca}^{2+}$ sensors), buffer, or transport proteins (Gifford et al. 2007). The $S$. cerevisiae Ssp120 is a protein with two EF-hand motifs. When ssp120 was knocked out, mutants became sensitive to $\mathrm{CaCl}_{2}$, but the reason is not clear (Babu et al. 2012). In our study, the mutant Sunf-MT6 was more sensitive to $\mathrm{Ca}^{2+}$ than was the wildtype strain. In addition, the mutant Sunf-MT6 is more severely inhibited by a broad range of stress conditions, including salt, sugar alcohols, sucrose, and antibiotic, compared with the wild type, suggesting that it has a general growth defect.

In $S$. cerevisiae, gene knockout indicates that Ssp120 is not essential for viability and growth (Sidhu et al. 1991), whereas Ss-Caf1 is involved in development of S. sclerotiorum. Sclerotial development is a very complicated process involving many signal pathways. The cAMP signal pathway appears important for sclerotial development, and high levels of cAMP inhibit the initiation of sclerotial formation (Rollins and Dickman 1998), while deletion of the adenylate cyclase $(\mathrm{sacl})$ gene produces aberrant sclerotia (Jurick and Rollins 2007), suggesting that a defined level of cAMP in hyphae is required for sclerotial development. The mitogen-activated protein kinase (MAPK) signal pathway is also involved in sclerotial development (Chen et al. 2004), and cAMP blocks MAPK activation and sclerotial development, via Rap-1, in a protein kinase A-independent manner (Chen and Dickman 2005). In addition, regulation of ambient $\mathrm{pH}$ is also important for sclerotial formation and, when the Pac1 transcription factor gene was subjected to targeted disruption, sclerotial development and maturation were aberrant (Rollins 2003). S. sclerotiorum also requires calcineurin for sclerotial development in an oxalic-acid-independent manner (Harel et al. 2006). Although Ss-Caf1 has a putative $\mathrm{Ca}^{2+}$-binding EF-hand motif, it is not likely to be involved in calcineurin-linked signal-transduction pathway, because silencing the calcineurin gene of $S$. sclerotiorum did not impair the formation of infection cushions (Harel et al. 2006).

Three genes of $S$. sclerotiorum have been identified, thus far, as being associated with both compound appressoria and sclerotial formation: Ss-ggt1 (a $\gamma$-glutamyltranspeptidase gene) (Li et al. 2012), sacl (a cAMP pathway adenylatecyclase gene) (Jurick and Rollins 2007), and rgbl (a type-2A phosphoprotein phosphatase [PP2A] B regulatory subunit gene) (Erental et al. 2007). Deletion of Ss-ggtl did not affect growth rate but the rind and cortex of fully mature sclerotia of $\Delta S s$-ggtl could be easily peeled away from the medulla ( $\mathrm{Li}$ et al. 2012). All of these mutant phenotypes were significantly different from that of Sunf-MT6, and the expression level of Ss-ggt1 in mutant SunfMT6 was not sharply reduced (Supplementary Fig. S10). The sacl-knockout mutant produced aberrant sclerotia which were slightly larger than those of the wild type and had a slower growth rate (Jurick and Rollins 2007); these phenotypes were similar to the mutant Sunf-MT6. In addition, the transcription of sacl in the Ss-cafl-disrupted mutant Sunf-MT6 was significantly reduced. However, the characteristics of the sacl-knockout mutant, including colony texture, hyphal branching, and a concentric pattern of sclerotial development (Jurick and Rollins 2007), were significantly different from those of Sunf-MT6. Targeted knockdown of $r g b l$ affects infection cushion formation, pathogenesis, and melanin biosynthesis (Erental et al. 2007). Furthermore, the PP2A inhibitor cantharidin leads to a slow growth rate and fewer but larger sclerotia (Erental et al. 2007). All of these phenotypic changes resemble those of Sunf-MT6. In addition, the expression level of $r g b l$ in the mutant Sunf-MT6 was significantly lower than that in the wild-type strain. Thus, the phenotype of the mutant Sunf-MT6 was more similar to the rgbl mutant than the other two mutants. Because PP2A activity is regulated by a MAPK pathway (Erental et al. 2007), we hy- 
pothesize that Ss-Caf1 works in a signaling pathway which links to the MAPK pathway.

The cuticle is an important barrier for plants against $S$. sclerotiorum and, like other pathogens, S. sclerotiorum developed a mechanism to breach this barrier. Many reports suggest that compound appressoria of $S$. sclerotiorum are essential for penetration of plant tissues (Huang et al. 2008; Jamaux et al. 1995; Lumsden and Dow 1973; Tariq and Jeffries 1984). The degree of compound appressorium complexity was directly correlated with physical resistance to penetration on the host surface, and the more physical resistance encountered by S. sclerotiorum, the more complex compound appressoria are formed (Tariq and Jeffries 1984). Botrytis cinerea, which is in the same family (Sclerotiniaceae) as S. sclerotiorum, is also a typical necrotrophic fungal pathogen. Simple appressoria have also been shown to function in penetration by $B$. cinerea. When infected by Botrytis cinerea mitovirus 1, this fungus exhibited pleiotropic phenotypes, including loss of infection cushion formation, and could not induce any lesions (Zhang et al. 2010). Mutant Sunf-MT6 can produce oxalic acid and CWDE abundantly but failed to form compound appressoria and penetrate healthy host tissues, suggesting that infection cushions are very important for successful infection. Further observation revealed that the wild-type strain need not form compound appressoria during its entry into wounded host tissues. The compound appressorium-defective mutant Sunf-MT6 can infect a host via wounds and induce typical lesions. Thus, Ss-Caf1 is associated with host penetration.

In addition to playing important roles in compound appressorial formation and sclerotial formation of S. sclerotiorum, SsCaf1 has the potential to function as a pathogenicity factor of S. sclerotiorum to trigger host cell death during early stages of infection. The programmed cell death (PCD) elicitors are crucial for early colonization by necrotrophic plant pathogens and involve defense responses of plants, including reactive oxygen species. In $S$. sclerotiorum, oxalic acid and endopolygalacturonase can induce PCD of host plant cells (Kim et al. 2008; Williams et al. 2011; Zuppini et al. 2005). The necrosis and ethylene-inducing peptide (NEP), a smaller secreted protein (approximately $24 \mathrm{kDa}$ ), which exists in diverse organisms, induces

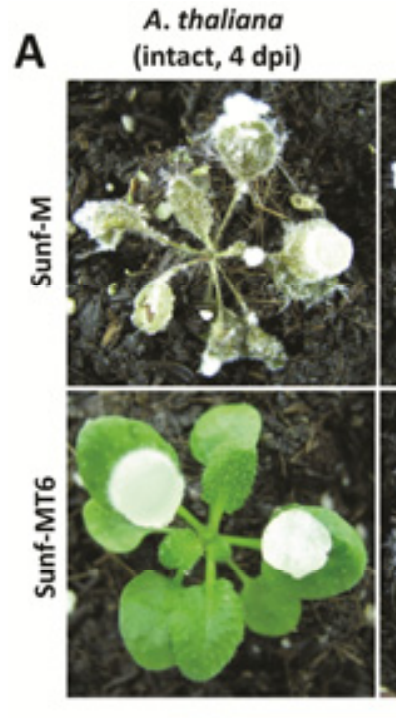

B
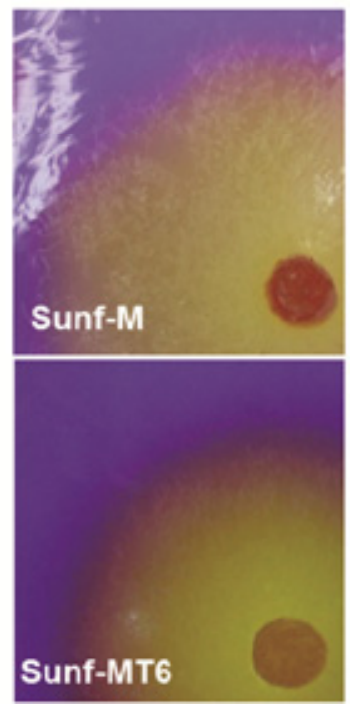

A. thaliana (wounded, 4 dpi)

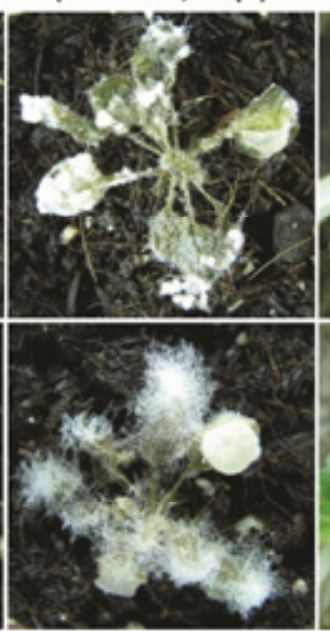

C
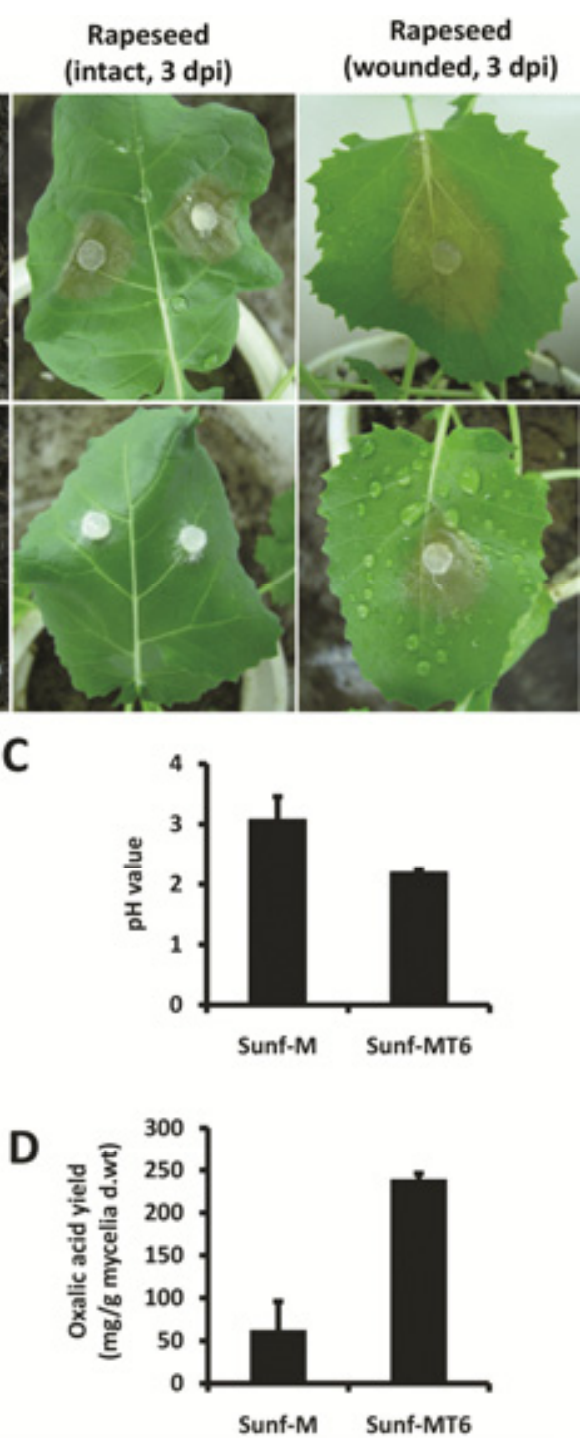

Fig. 6. Pathogenicity assay of mutant Sunf-MT6. A, Pathogenicity on Arabidopsis thaliana and rapeseed, showing that the mutant could not penetrate intact plants but could induce lesions on wounded leaves. Plants were placed in an incubator at $20^{\circ} \mathrm{C}$ with $90 \%$ relative humidity after inoculation. The wild-type strain Sunf-M was used as a control. B, Qualitative determination of acid produced by the wild-type strain Sunf-M and the mutant Sunf-MT6 on potato dextrose agar containing $0.01 \%$ (wt/vol) bromophenol blue dye as an ambient $\mathrm{pH}$ indicator. The presence of yellow during hyphal extension indicates that acid was produced. C, Ambient pH of cultures of strain Sunf-M and mutant Sunf-MT6 in potato dextrose broth (PDB). D, Yield of oxalic acid produced by the wild-type strain Sunf-M and mutant Sunf-MT6 of Sclerotinia sclerotiorum in PDB was measured by high-performance liquid chromatography. Those two strains were cultured for 3 days and spent broth was collected for oxalic acid production and $\mathrm{pH}$ measurement. Bars indicate standard error. 
necrotic cell death and a multitude of defense responses in plants (da Silva et al. 2011; Pemberton and Salmond 2004). Two NEPs have also been isolated from $S$. sclerotiorum and confirmed to elicit necrosis when expressed transiently in tobacco leaves (Bashi et al. 2010). Our results showed that Ss-Caf1 has a secretory property, and Ss-cafl shows strong expression at 4 hpi after contacting host leaves. In addition, expression of a signalpeptide-deleted Ss-Caf1 in N. benthamiana led to cell death of plants. This implied that Ss-Caf1 has the potential to enter host cells to interact with host proteins or other substances and trigger host cell death to create a favorable environment for fungal growth and, thus, play an important role in pathogenicity.

In summary, we identified a gene, Ss-cafl, which encodes a secretory protein with an EF-hand motif, and confirmed its roles in pathogenicity and sclerotial development of S. sclerotiorum. Ss-Caf1 could induce cell death in plants when expressed in host cells, which should benefit S. sclerotiorum during colonization and when obtaining nutrition from the plant.
Hence, blocking expression of Ss-cafl could be an efficient strategy to control Sclerotinia diseases. Our findings offer important clues to help decipher the infection process and sclerotial development of $S$. sclerotiorum, and are likely to offer insights into the study of functional homologs of Ss-Caf1 in other pathogens. To determine the overall contribution of SsCaf1 to the biology of $S$. sclerotiorum, future studies may focus on identifying potential proteins that can interact with Ss-Caf1 to reveal the upstream and downstream signal transduction components of Ss-Caf1.

\section{MATERIALS AND METHODS}

Strains and cultural conditions.

S. sclerotiorum wild-type strain Sunf-M is pathogenic to its hosts and produces sclerotia. It was obtained from a sunflower (Helianthus annuus) in Hohhot, Inner Mongolia, China. Strain Sunf-M was cultured on PDA (Difco, Detroit) at $20^{\circ} \mathrm{C}$ and
A

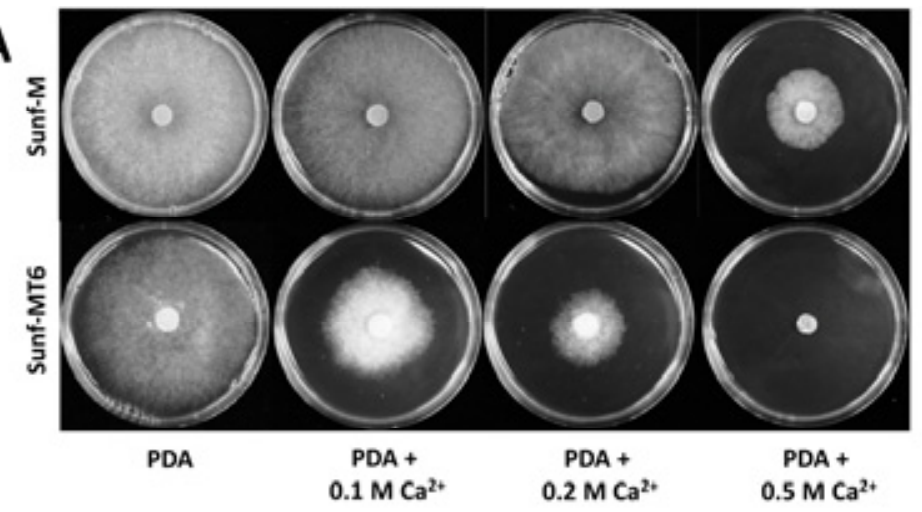

B

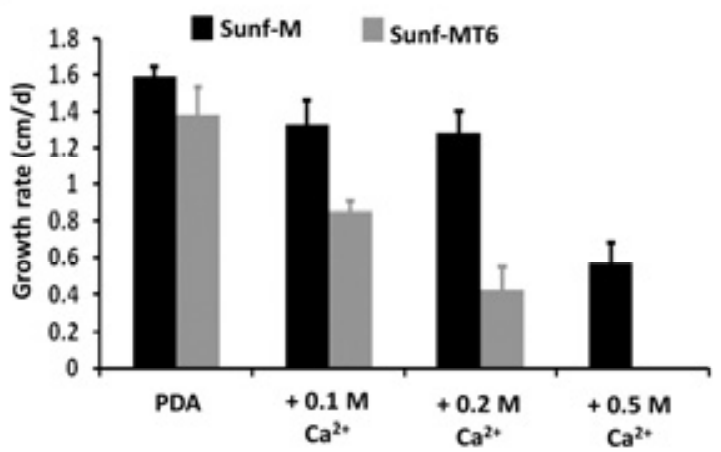

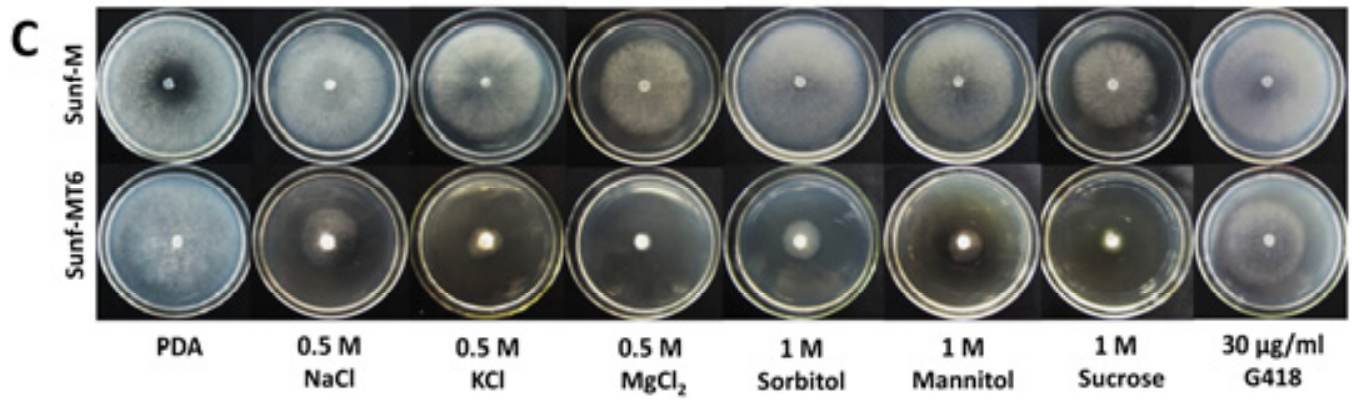

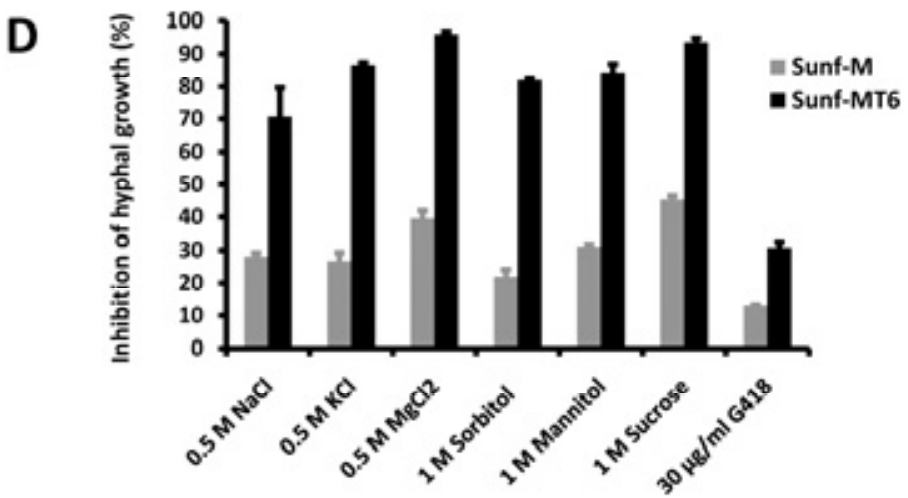

Fig. 7. A, Phenotype and $\mathbf{B}$, percent growth inhibition of the wild-type strain Sunf-M and mutant Sunf-MT6 on potato dextrose agar (PDA) containing CaCl 2 Strains were cultured for 4 days at $20^{\circ} \mathrm{C}$ prior to photography. The growth of mutant Sunf-MT6 is slightly slower than that of the wild-type strain on PDA. Compared with growth on PDA, growth of Sunf-MT6 was inhibited by 40 and $70 \%$ on PDA containing 0.1 and $0.2 \mathrm{M} \mathrm{Ca}^{2+}$, respectively, and was fully inhibited when grown on $0.5 \mathrm{M} \mathrm{Ca}^{2+}$. However, there was a only slight growth inhibition of Sunf-M on PDA containing 0.1 or $0.2 \mathrm{M} \mathrm{Ca}^{2+}$, and its growth on PDA containing $0.5 \mathrm{M} \mathrm{Ca}^{2+}$ was significantly suppressed. $\mathbf{C}$ and $\mathbf{D}$, Phenotype and percent growth inhibition, respectively, of Sunf-M and Sunf-MT6 on PDA containing $0.5 \mathrm{M}$ salts $\left(\mathrm{NaCl}, \mathrm{KCl}\right.$, and $\mathrm{MgCl}_{2}$ ), $1 \mathrm{M}$ sugar alcohols (sorbitol and mannitol), $1 \mathrm{M}$ sucrose, and $\mathrm{G} 418$ at $30 \mu \mathrm{g} / \mathrm{ml}$ and $20^{\circ} \mathrm{C}$ for 4 days, showing that Sunf-MT6 is more sensitive to medium containing substance than that of Sunf-M. Two strains were grown on media for 4 days at $20^{\circ} \mathrm{C}$ prior to photography. 
stored on PDA slants at $4^{\circ} \mathrm{C}$. Sclerotia were collected, air dried, and stored at $-20^{\circ} \mathrm{C}$. All transformants were maintained on PDA supplemented with hygromycin B (Sigma-Aldrich, St. Louis) at $50 \mu \mathrm{g} / \mathrm{ml}$ or G418 (Sigma-Aldrich) at $100 \mu \mathrm{g} / \mathrm{ml}$.

\section{Nucleic acid extraction and RT-PCR analysis.}

The fungal hyphae or plant tissues were collected and ground to a fine powder in liquid nitrogen. Genomic DNA was extracted with the cetyltrimethylammonium bromide method as described by Sambrook and Russell (2001). Total RNA was isolated with the Trizol reagent (Takara, Dalian, China) and treated with DNaseI. First-strand cDNA was synthesized following instructions of the RevertAid First-Strand cDNA synthesis kit (Thermo Fisher Scientific Inc., Waltham, MA, U.S.A.), and the cDNA was used as a template for RT-PCR or qPCR.

To evaluate the gene expression levels in S. sclerotiorum, relative quantification was performed with the SYBR Green RT-PCR on CFX96TM Real time System (Bio-Rad, Hercules, CA, U.S.A.). The expression level of $S$ s-cafl was analyzed via qPCR with the primer pairs QF/QR (Supplementary Table S1). Primer pairs Ggt1F/Ggt1R, Sac1F/Sac1R, and Rgb1F/Rgb1R were used to test the expression level of genes Ss-ggtl, sacl, and $r g b l$, respectively. Total cDNA abundance in the samples was normalized using the actin gene as a control, which was amplified by primer pair ActinF/ActinR.

\section{Cloning and analysis of T-DNA flanking sequence.}

The T-DNA insertion copy number in the mutant Sunf-MT6 was analyzed with Southern hybridization according to the method described by $\mathrm{Li}$ and associates (2005). Briefly, 15- $\mu \mathrm{g}$ genomic DNA samples of Sunf-MT6 and the negative control
Sunf-M were completely digested with SacI. Plasmid pTFCM (Li et al. 2005) was digested with $\mathrm{SacI}$ and used as a positive control. The digested fragments were separated on a $0.8 \%$ gel and transferred onto positively charged nylon membranes. The $h p h$ amplified from vector pTFCM with specific primer pair $(\mathrm{HphF} / \mathrm{HphR})$ was $\alpha-{ }^{32} \mathrm{P}$-labeled as a probe using a random primer kit (Takara).

hiTail-PCR, described by Liu and Chen (2007), was performed to amplify the T-DNA flanking sequences from genomic DNA of the mutant. Primers LAD1-1 to LAD1-4, AC1, and RB-0a, RB-1a, and RB-2a were designed as described by Liu and Chen (2007), and specific primers XLB1, XLB2, and XLB3 were designed based on sequences of the T-DNA left border. Primer pairs TF/TR (extension 30 s), TF/XLB3 (extension $30 \mathrm{~s}$ ), and GUSF/TR (extension $2 \mathrm{~min}$ ) were employed to confirm the T-DNA insertion site. Primer pair TF/TR was used to analyze gene transcription by RT-PCR, and the actin gene (control) was amplified with the primer pair ActinF/ActinR.

The sequences referenced in this study were retrieved from the National Center for Biotechnology Information GenBank database. ProtParam was used to predict the molecular weight and isoelectric point of the proteins. The amino acid sequence was analyzed with SignalP server, version 3.0 (Bendtsen et al. 2004) and TMHMM server, version 2.0, to predict potential signal peptide and trans-membrane domains. Amino acid sequences were scanned with Scanprosite to predict protein motifs and functional sites. The Phyre 2 servers were used to predict the three-dimensional structure of protein sequences with a homology modeling method (Kelley and Sternberg 2009). The structural images of proteins were created using the PyMOL molecular viewer. Sequence alignments and phyloge-

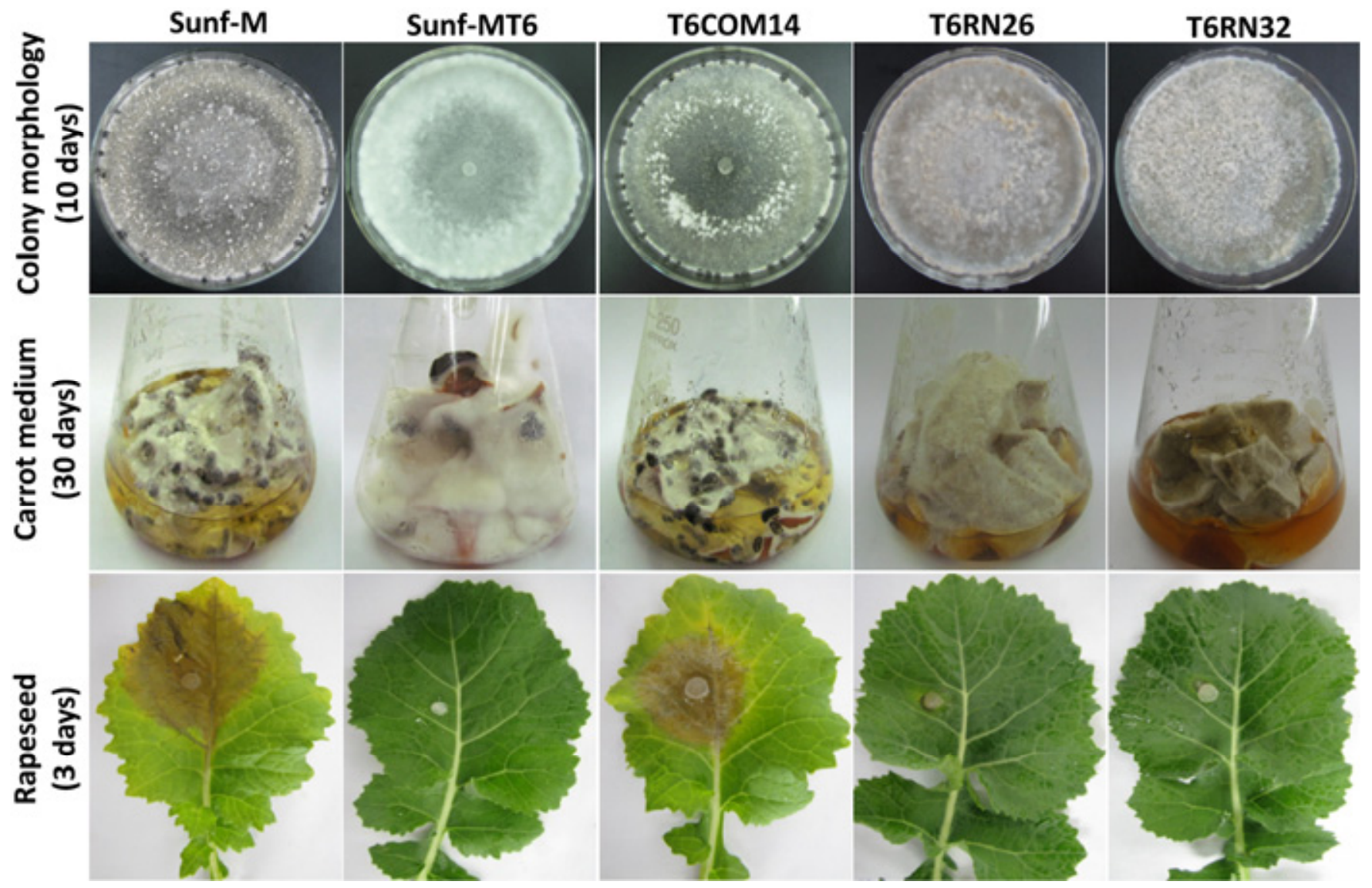

Fig. 8. Colony morphology (on potato dextrose agar at $20^{\circ} \mathrm{C}$ for 10 days), sclerotial production (on carrot root at $20^{\circ} \mathrm{C}$ for 30 days), and pathogenicity assay (at $20^{\circ} \mathrm{C}$ for 3 days) of Ss-cafl mutants of Sclerotinia sclerotiorum. T6COM14 is a complemented mutant of Sunf-MT6, and TRN26 and TRN32 are Ss-caf1 RNAi-silencing mutants. 
A
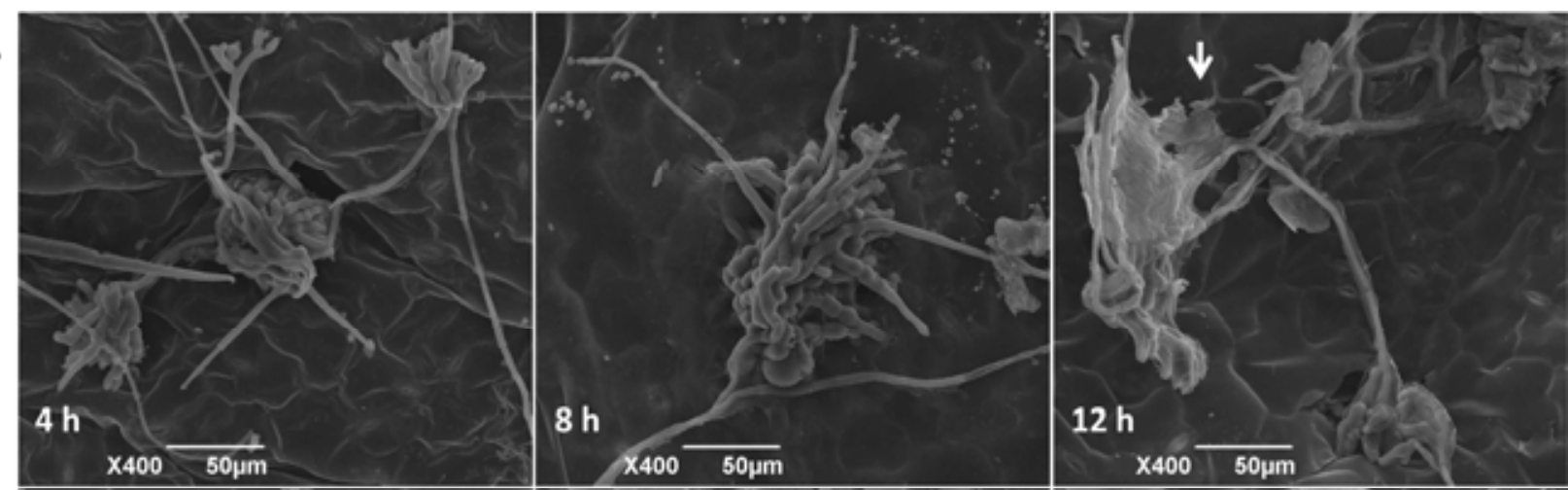

B
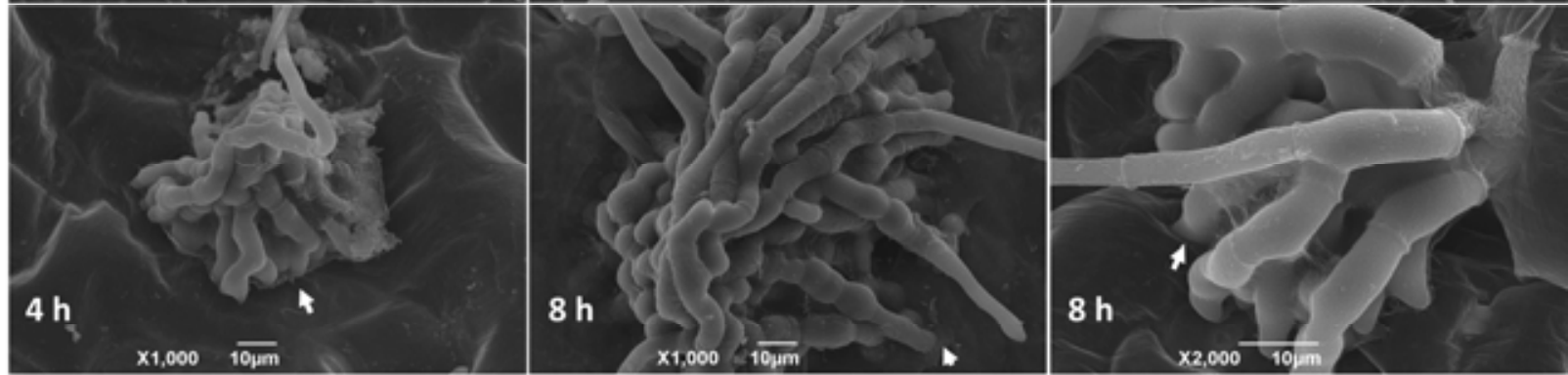

C

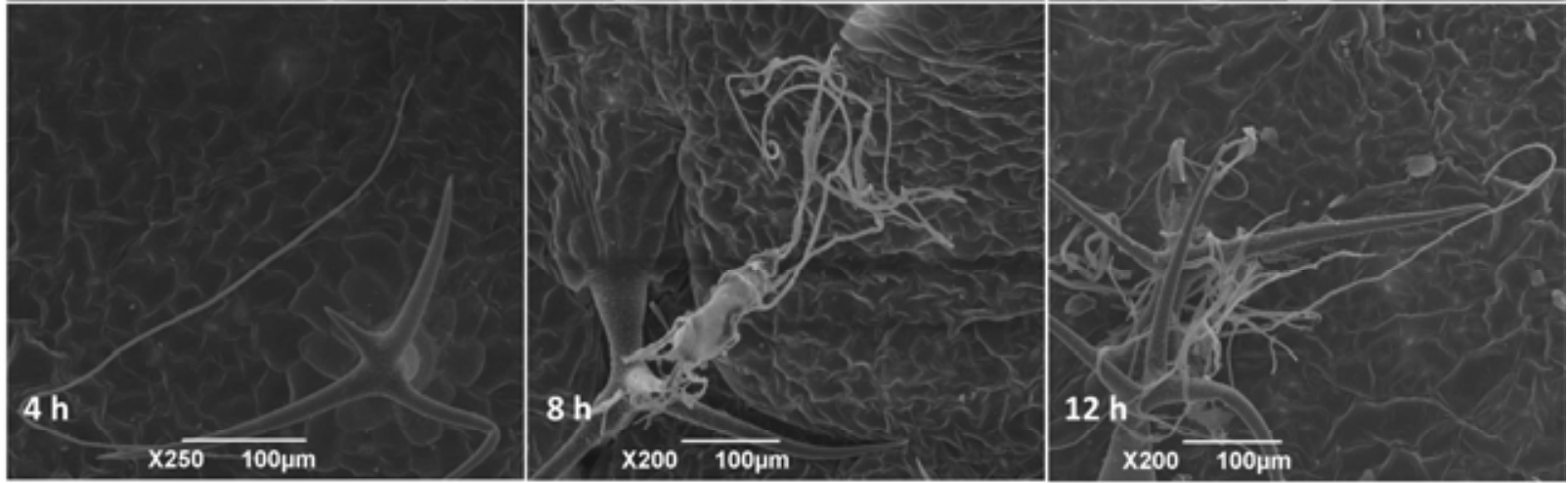

D

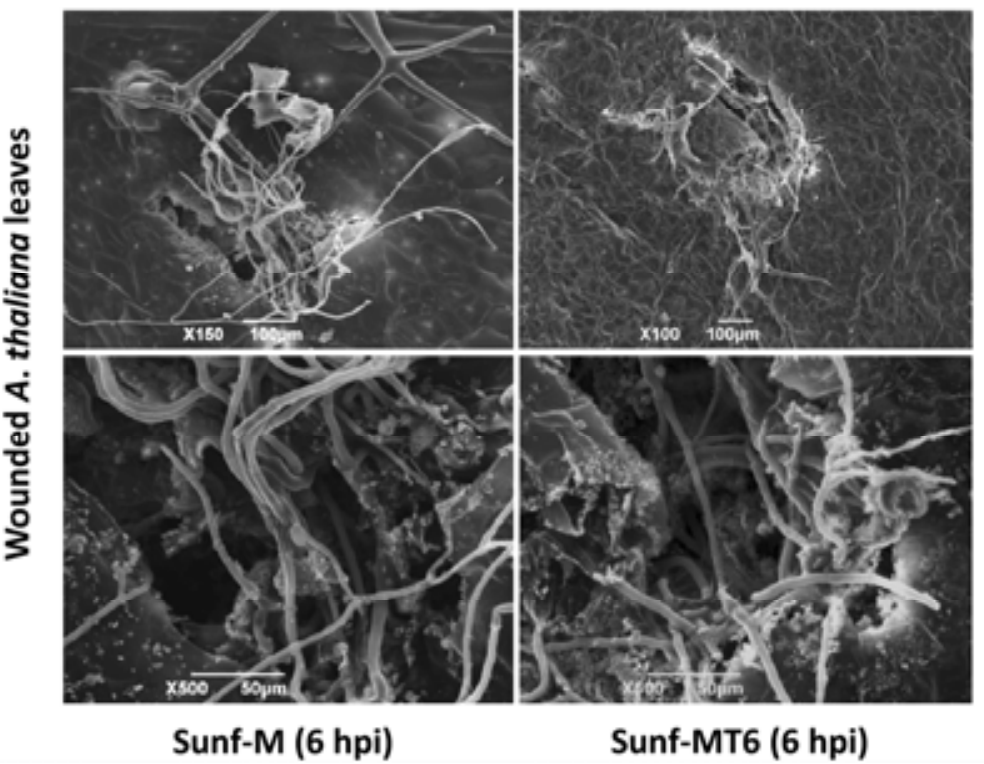

$\mathbf{E}$

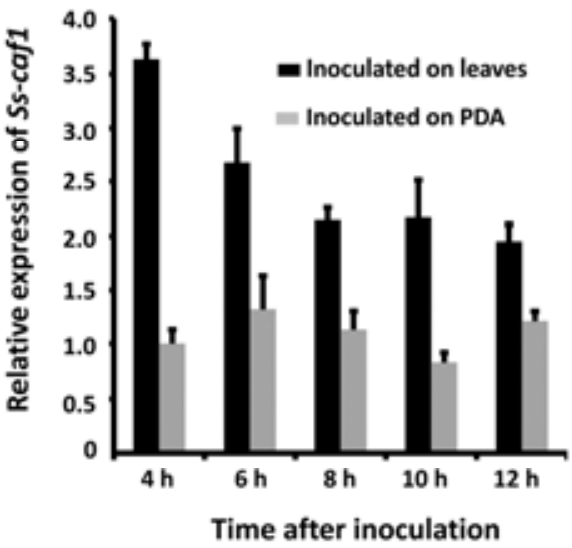

Fig. 9. Infection processes of the wild-type strain Sunf-M and mutant Sunf-MT6 on intact Arabidopsis thaliana leaves. A, Infection process of the wild-type strain Sunf-M on intact A. thaliana leaves. Arrow indicates sticky mucilage covering the surface of the compound appressoria. B, Compound appressoria of the wild-type strain Sunf-M. Arrows indicate compound appressoria penetrated into the epidermis of leaves. C, Infection process of mutant Sunf-MT6 on intact A. thaliana leaves. D, Infection processes of the wild-type strain Sunf-M and mutant Sunf-MT6 on wounded leaves of $A$. thaliana observed with scanning electron microscopy. Bottom panels are partial enlarged images of the top panels. E, Relative transcript accumulation patterns of Ss-cafl was assessed by reverse-transcription quantitative polymerase chain reaction amplification for infected A. thaliana (dark columns) and for the fungus growing on cellophane placed in potato dextrose agar plates (gray columns). Total cDNA abundance in the samples was normalized using actin as an endogenous reference. The relative expression level of Ss-cafl in Sunf-M which was cultured on cellophane for $4 \mathrm{~h}$ was assigned a value of 1 . Bars indicate standard error (three replications). 
netic analyses were carried out using DNAMAN, CLUSTAL_W (Thompson et al. 1994), and BLAST software. Based on the aligned sequences, phylogenetic trees were constructed using the neighbor-joining method in the program MEGA, version 5.0 (Tamura et al. 2011).

\section{Construction of complementation and} gene silencing vectors and transformation.

For construction of the $S s$-cafl complementation vector, a fragment containing the gene $S s$-cafl, its promoter, and its $3^{\prime}$ untranslated region was amplified with the primer pair COMF/COMR. The sequenced PCR product was digested with $K p n I$ and $S m a I$, then ligated into $K p n I / S m a I$-digested pCIT (Yu et al. 2012) to generate vector pCITC1. A fragment comprising promoter, coding sequence, untranslated region, and terminator was obtained by digesting pCITC1 with $X b a \mathrm{I}$ and $K p n I$, then ligated into $X b a \mathrm{I} / K p n I-d i g e s t e d ~ p C A M B I A-$ 3300. Finally, a 2.0-kb G418 resistance gene cassette was inserted at the enzyme recognition site $\mathrm{XbaI}$ of pCAMBIA3300 to generate the complementation vector pT6COM. The complementation vector was transformed into mutant Sunf-MT6 through ATMT (Yu et al. 2012). Candidate transformants were screened on PDA containing G418 at $100 \mu \mathrm{g} / \mathrm{ml}$ and hygromycin $\mathrm{B}$ at $100 \mu \mathrm{g} / \mathrm{ml}$ and confirmed by amplification of $h p h$ with primer pair $\mathrm{HphF} / \mathrm{HphR}$, and the $\mathrm{G} 418$ resistance gene with primer pair $\mathrm{NeoF} / \mathrm{NeoR}$. RT-PCR amplification with primer pair PF/PR was used to analyze the expression of Ss-cafl in transformants.
To construct the $S s$-cafl silencing vector, primer pair SI-SF and SI-SR were used to amplify a 405-bp Ss-cafl coding sequence to obtain the sense fragments. The PCR product was sequenced and digested with PstI and BamHI, then ligated into vector pCIT between the intron (an intron from gene EAA75655.1 in G. zeae) and PtrpC, to produce vector pCITT6-1. The primers SI-AF and SI-AR were designed to amplify the same coding sequence to obtain the antisense fragment, and the sequence was verified as above. PCR products were digested with HindIII and ClaI, then ligated into HindIII/ClaIdigested pCITT6-1 between the intron and TrpC to yield vector pCITT6-2. pCITT6-2 was digested with SacI and XhoI to obtain a fragment in which the two 405-bp fragments were inserted in opposite orientations between PtrpC and TtrpC. This fragment was then ligated between $S a c I$ and XhoI sites of pCAMBIA3300 , which carries $h p h$, to create the $S s$-cafl-silencing vector pT6RN. The vector pT6RN was transformed into the wild-type strain Sunf-M through ATMT (Yu et al. 2012). Candidate transformants were screened on PDA containing hygromycin B at $100 \mu \mathrm{g} / \mathrm{ml}$. The expression level of Ss-cafl was analyzed via qPCR with primer pair $\mathrm{QF} / \mathrm{QR}$.

\section{Phenotypic analysis.}

To measure the growth rate, compare colony morphology, and observe sclerotial formation, S. sclerotiorum strains were cultured on plates containing $15 \mathrm{ml}$ of PDA at $20^{\circ} \mathrm{C}$. Sclerotia were collected and dried at $37^{\circ} \mathrm{C}$ for 2 weeks, and the weight and numbers of sclerotia were recorded. Three mycelial plugs

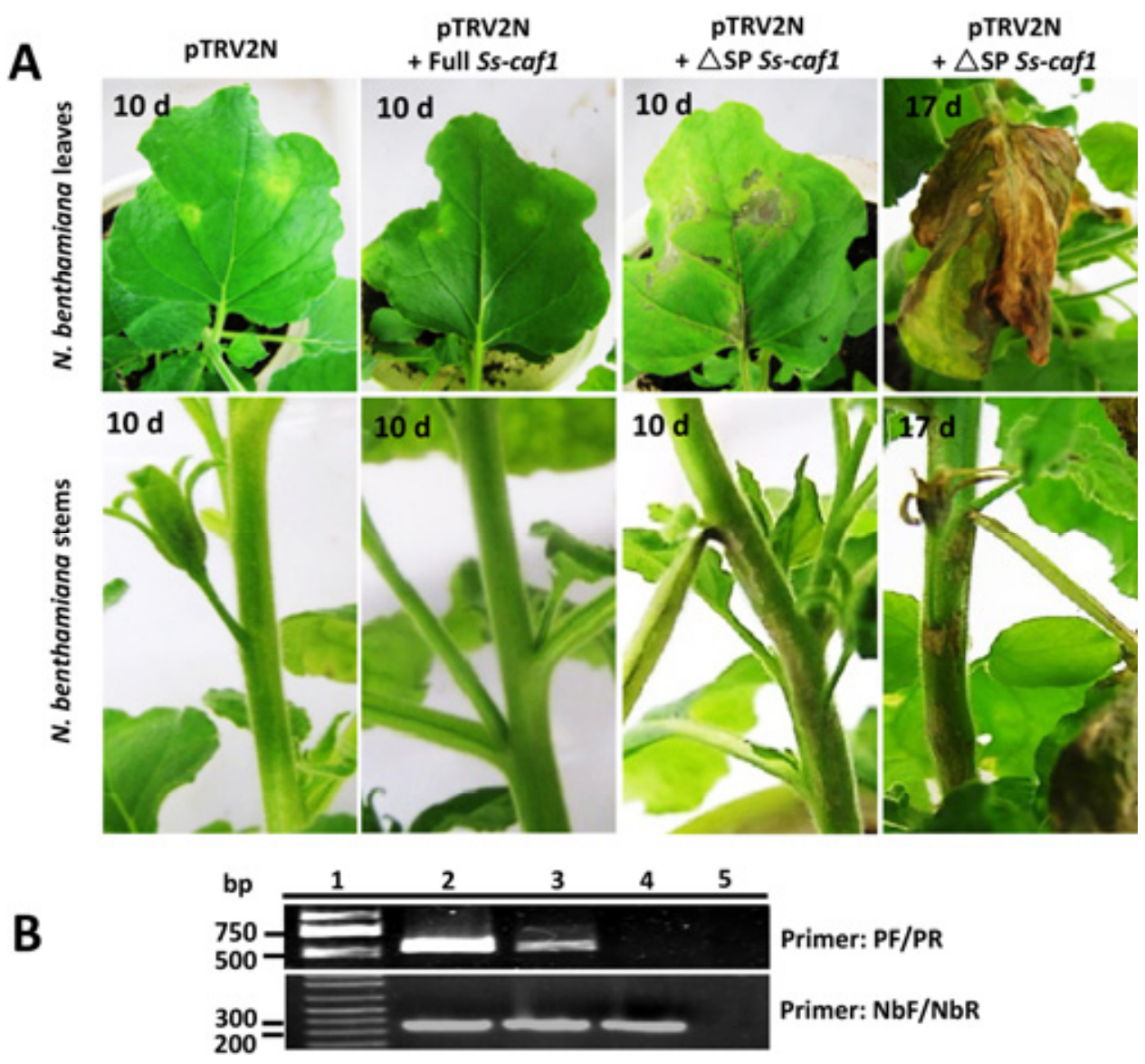

Fig. 10. Expression of Ss-cafl-induced cell death in Nicotiana benthamiana. A, N. benthamiana infiltrated with cultures of Agrobacterium containing empty vector pTRV2, expression vector pTRVN-T6 with signal peptide, and expression vector pTRV2N-T6 SSP without signal peptide. B, Reversetranscription polymerase chain reaction confirmation of the expression of Ss-cafl (upper panel) in N. benthamiana; actin of N. benthamiana was detected as a control (lower panel). Lane 1, DNA ladder. Sizes of molecular mass standards are indicated to the left of each panel (upper panel: DL2000 Ladder Marker, Takara; lower panel: 1-kb Ladder Marker, NEB). Lane 2, pTRV2N + $\Delta$ SP Ss-caf1. Lane 3, pTRV2N + Full Ss-caf1. Lane 4, pTRV2N. Lane $5, \mathrm{H}_{2} \mathrm{O}$. 
were inoculated into $100 \mathrm{~g}$ of sterilized carrot roots per flask to observe sclerotial formation.

\section{Pathogenicity assay.}

Plants used in this study were routinely grown in the greenhouse. To test pathogenicity of $S$. sclerotiorum strains, mycelia plugs ( $5 \mathrm{~mm}$ in diameter) obtained from actively growing colony edges were used to inoculate leaves of $A$. thaliana, rapeseed, pak choi cabbage, hot pepper, tomato, cucumber, or soybean. Strain Sunf-M was tested as a control under the same conditions. The inoculated plants were maintained at $90 \%$ relative humidity. For $A$. thaliana Col-0, the lesions were evaluated at $4 \mathrm{dpi}$ and, for other plants, lesion diameters were measured at 3 dpi. All analyses of biological characteristics involved five replicates for each treatment. For the wounded leaf treatments, three small wounds were made on the leaves with a sterilized needle prior to inoculation, and the mycelial plugs were placed over the wounds.

\section{Detection of sensitivity to salts, sugar alcohols, and sugar.}

The wild-type strain Sunf-M and mutant Sunf-MT6 were cultured on PDA; PDA amended with $0.1,0.2$, or $0.5 \mathrm{M} \mathrm{CaCl}_{2}$; or media amended with $0.5 \mathrm{M}$ salts $\left(\mathrm{NaCl}, \mathrm{KCl}\right.$, and $\left.\mathrm{MgCl}_{2}\right)$, $1 \mathrm{M}$ sugar alcohols (sorbitol and mannitol), $1 \mathrm{M}$ sucrose, or G418 at $30 \mu \mathrm{g} / \mathrm{ml}$. The $\mathrm{pH}$ of all media was adjusted to 6.5 . The hyphal growth was measured daily and the percentage growth inhibition (PGI) was calculated based on the formula PGI $=(A-B) / A \times 100 \%$, where $A$ represents the growth rate on PDA plate and $B$ represents the growth rate of the same strain on PDA containing different substances.

\section{TEM and immunoelectron microscopy.}

Fresh mycelia and sclerotia were collected and cut into small pieces ( 3 by $3 \mathrm{~mm}$ ). To observe the internal structure of sclerotia with TEM or determine protein location by immunoelectron microscopy, samples of $S$. sclerotiorum were fixed and sectioned as described by $\mathrm{Yu}$ and associates (2012). For immunoelectron microscopy, the rabbit polyclonal antibodies anti-Ss-Caf1 were prepared as described below, and the secondary antibody was goat anti-rabbit immunoglobulin absorbed to 15 -nm gold particles (Biocell Research Laboratories, Cardiff, U.K.).

\section{Protein extraction and Western blot analysis.}

Total soluble proteins of $S$. sclerotiorum were extracted as previously described (Harel et al. 2005). To isolate the secreted proteins, $S$. sclerotiorum was cultured in PDB for 3 days. The culture broth was centrifuged at $10,000 \mathrm{rpm}$ for $5 \mathrm{~min}$ to remove hyphal fragments. Secreted proteins in the fermentation liquid were precipitated with solid ammonium sulfate at $80 \%$ saturation and incubated overnight at $4^{\circ} \mathrm{C}$. The precipitated secreted proteins were obtained by centrifugation for 5 min at 10,000 rpm, dissolved in phosphate-buffered saline (137 mM NaCl, $2.7 \mathrm{mM} \mathrm{KCl}, 10 \mathrm{mM} \mathrm{Na}_{2} \mathrm{HPO}_{4}$, and $2 \mathrm{mM}$ $\mathrm{KH}_{2} \mathrm{PO}_{4}$ ), and then purified by dialysis. Protein concentrations were quantified with the BCA Protein Assay Kit (Beyotime Biotech, Haimen, China). For the Western blot, $50 \mu \mathrm{g}$ of extracted protein was separated with $12 \%$ sodium dodecyl sulfate polyacrylamide gel electrophoresis and transferred to a polyvinylidene difluoride membrane $(0.22 \mu \mathrm{m})$ (Millipore, Bedford, MA, U.S.A.) using a Trans-blot SD semidry electrophoretic transfer cell (Bio-Rad). The rabbit polyclonal anti-SsCaf1 antibody, which has high specificity to Ss-Caf1, was used as the primary antibody, and the secondary antibody was a goat anti-rabbit immunoglobulin $\mathrm{G}$ conjugated with alkaline phosphatase. The membranes were incubated overnight at $4^{\circ} \mathrm{C}$ in TBST $(20 \mathrm{mM}$ Tris- $\mathrm{HCl}, 150 \mathrm{mM} \mathrm{NaCl}$, and $0.05 \%$ [vol/vol] Tween 20) containing 5\% nonfat dry milk, washed three times with TBST, then incubated at room temperature for $2 \mathrm{~h}$ with the primary antibody diluted 1:1000. The membranes were washed, then reacted with the secondary antibody (diluted 1:10,000 in TBST containing 5\% nonfat milk) for $1 \mathrm{~h}$ at room temperature. The bound antibodies were detected using the BCIP/NBT color development substrate (Promega, Beijing) after the membrane was washed three times with $20 \mathrm{mM}$ Tris$\mathrm{HCl}$ and $150 \mathrm{mM} \mathrm{NaCl}$.

\section{Assays of oxalic acid, pectinases, cellulases, proteases, and amylases.}

To quantitatively assay the oxalic acid production of strains Sunf-M and Sunf-MT6 of S. sclerotiorum, two 9-mm-diameter mycelial plugs of each strain were placed into $250-\mathrm{ml}$ flasks containing $50 \mathrm{ml}$ of PDB and incubated at $20^{\circ} \mathrm{C}$ with shaking at $150 \mathrm{rpm}$. Three flasks of broth of each strain were retrieved after incubation for 3 days and the $\mathrm{pH}$ of the culture filtrates was measured. The concentration of oxalic acid in the cultural filtrates was assessed using high-performance liquid chromatography (Zhang et al. 2010) and yield was expressed as milligrams of oxalic acid per gram of dry mycelia (mycelia were dried for $48 \mathrm{~h}$ at $60^{\circ} \mathrm{C}$ ). The assay was repeated three times.

For qualitative evaluation of acid production by S. sclerotiorum, mycelial plugs were placed onto PDA amended with $0.01 \%$ (wt/vol) bromophenol blue dye as an ambient $\mathrm{pH}$ indicator (Godoy et al. 1990). Acid production was evaluated by the presence of yellow in the colony.

The production of pectinases was tested as described by Zhang and associates (2010). Mycelial plugs were placed on 9-cm-diameter petri dishes containing $0.1 \%$ polygalacturonic acid (wt/vol). After incubation at $45^{\circ} \mathrm{C}$ for $12 \mathrm{~h}$, the plugs were removed from each dish and the dishes were then flooded with ruthenium red solution $(0.03 \%, \mathrm{wt} / \mathrm{vol})$ and incubated for $2 \mathrm{~h}$ at $4^{\circ} \mathrm{C}$. Pectinase activities were evaluated by the presence of a clear zone under the area occupied by the mycelial plugs.

Total secreted cellulases and proteases activities were determined according to the methods of Harel and associates (2006). Cellulase activities were observed as orange halos on a red background and protease activities were indicated by a clear zone around the colony.

Amylases detection medium contained beef extract at 2 $\mathrm{g} /$ liter, casein tryptone at $17.5 \mathrm{~g} /$ liter, amylum at $1.5 \mathrm{~g} / \mathrm{liter}$, and 1 agar at $5 \mathrm{~g} /$ liter. Cultures were grown for 24 to $48 \mathrm{~h}$ at $20^{\circ} \mathrm{C}$; then, the plates were stained with Gram's iodine solution $(2 \%$ iodine and $3 \%$ potassium iodide in $70 \%$ ethanol) and destained several times with water. Amylase activities were determined by the presence of a clear zone of the colony on a blue background.

\section{Infection process assay.}

The infection process on the hosts was observed with both SEM and light microscopy. Actively growing mycelial plugs ( $5 \mathrm{~mm}$ in diameter) of $S$. sclerotiorum were inoculated on healthy and wounded leaves of $A$. thaliana Col-0. A needle had been used to create three small holes as the wounds on the leaves. The samples were collected at 4, 8, 12, 16, 20, and 24 hpi. For SEM observations, leaves from the inoculation sites were cut into small pieces ( 3 by $3 \mathrm{~mm}$ ); 10 pieces of tissue for each sample were collected. Samples for SEM were processed and examined as described by Zhang and associates (2010). For light microscopy, leaf samples were stained with trypan blue as described below. Infected leaves were fixed and decolorized in acetic acid/ethanol (1:3, vol/vol) and stained with $0.05 \%$ trypan blue in a lactophenol solution (20\% lactic acid, $20 \%$ phenol, $40 \%$ glycerol, and $20 \%$ water) overnight. The staining solution was then removed and the pieces of tissue were mounted in $50 \%$ glycerol on glass slides. 


\section{Expression of gene Ss-caf 1}

in Nicotiana benthamiana via TRV-based vectors.

$N$. benthamiana plants were routinely grown in pots at $25^{\circ} \mathrm{C}$ in the greenhouse. TRV-based vectors pTRV1 and pTRV2 were used for gene expression in $N$. benthamiana as previously described (Liu et al. 2002), with minor modifications. An XcmI enzyme recognition site was added in vector pTRV2 to generate a new vector, pTRV2N. The ORF of Ss-cafl, with and without a signal peptide sequence, was cloned with primer pairs PF/PR and PF2/PR, respectively. These two purified PCR products were ligated into the $X c m I$ enzyme recognition site of vector pTRV2N, thus generating pTRV2N-T6 (with signal peptide) and pTRV2N-T6 $\Delta$ SP (without signal peptide sequence). Agrobacterium tumefaciens GV3101 cultures containing pTRV1 and pTRV2N-T6 (or pTRV2N-T6 $\Delta S P$ ) plasmids were mixed in a 1:1 ratio and infiltrated into four-leaf-stage $N$. benthamiana leaves using needleless syringes. In addition, bacterial cultures composed of equal volumes of pTRV1 and pTRV2N were used as controls. Throughout the experiment, the responses of $N$. benthamiana were monitored daily. The experiment was repeated five times, and each treatment included five independent plants, with observation taken of necrotic plants. Leaves of $N$. benthamiana that were infiltrated by $A$. tumefaciens for 5 days were collected to isolate the total RNA. Gene Ss-cafl expression in N. benthamiana was confirmed by RT-PCR with primer pair PF/PR, and the actin gene (control) of $N$. benthamiana was amplified with the primer pair $\mathrm{NbF/NbR.}$

\section{ACKNOWLEDGMENTS}

This research was supported by the Natural Science Foundation of China (31071647), the Special Fund for Agro-scientific Research in the Public Interest (grant number 201103016), the Program for Changjiang Scholars and Innovative Research Team in University of China (IRT1247), and the earmarked fund for China Agriculture Research System (CARS13). We thank S. A. Ghabrial at the University of Kentucky and T. Hsiang at the University of Guelph for their critical readings of the manuscript and anonymous reviewers for constructive and helpful comments.

\section{LITERATURE CITED}

Adams, P. B., and Ayers, W. A. 1979. Ecology of Sclerotinia species. Phytopathology 69:896-899.

Babu, M., Vlasblom, J., Pu, S., Guo, X., Graham, C., Bean, B. D., Burston, H. E., Vizeacoumar, F. J., Snider, J., Phanse, S., Fong, V., Tam, Y. Y., Davey, M., Hnatshak, O., Bajaj, N., Chandran, S., Punna, T., Christopolous, C., Wong, V., Yu, A., Zhong, G., Li, J., Stagljar, I., Conibear, E., Wodak, S. J., Emili, A., and Greenblatt, J. F. 2012. Interaction landscape of membrane-protein complexes in Saccharomyces cerevisiae. Nature 489:585-589.

Bashi, Z. D., Hegedus, D. D., Buchwaldt, L., Rimmer, S. R., and Borhan, M. H. 2010. Expression and regulation of Sclerotinia sclerotiorum necrosis and ethylene-inducing peptides (NEPs). Mol. Plant Pathol. 11:43-53.

Bendtsen, J. D., Nielsen, H., von Heijne, G., and Brunak, S. 2004. Improved prediction of signal peptides: SignalP 3.0. J. Mol. Biol. 340:783-795.

Boland, G. J., and Hall, R. 1994. Index of plant hosts of Sclerotinia sclerotiorum. Can. J. Plant Pathol. 16:93-108.

Bolton, M. D., Thomma, B. P. H. J., and Nelson, B. D. 2006. Sclerotinia sclerotiorum (Lib.) de Bary: biology and molecular traits of a cosmopolitan pathogen. Mol. Plant Pathol. 7:1-16.

Cessna, S. G., Sears, V. E., Dickman, M. B., and Low, P. S. 2000. Oxalic acid, a pathogenicity factor for Sclerotinia sclerotiorum, suppresses the oxidative burst of the host plant. Plant Cell 12:2191-2200.

Chen, C., and Dickman, M. B. 2005. cAMP blocks MAPK activation and sclerotial development via Rap-1 in a PKA-independent manner in Sclerotinia sclerotiorum. Mol. Microbiol. 55:299-311.

Chen, C., Harel, A., Gorovoits, R., Yarden, O., and Dickman, M. B. 2004. MAPK regulation of sclerotial development in Sclerotinia sclerotiorum is linked with $\mathrm{pH}$ and cAMP sensing. Mol. Plant-Microbe Interact. $17: 404-413$ da Silva, L. F., Dias, C.V., Cidade, L.C., Mendes, J. S., Pirovani, C. P. Alvim, F. C, Pereira, G. A. G., Aragão, F. J. L., Cascardo, J. C. M., and Costa, M. G. C. 2011. Expression of an oxalate decarboxylase impairs the necrotic effect induced by Nep1-like protein (NLP) of Moniliophthora perniciosa in transgenic tobacco. Mol. Plant-Microbe Interact. 24:839-848.

de Alba, E., and Tjandra, N. 2004. Structural studies on the $\mathrm{Ca}^{2+}$-binding domain of human nucleobindin (Calnuc). Biochemistry 43:1003910049.

Erental, A., Harel, A., and Yarden, O. 2007. Type 2A phosphoprotein phosphatase is required for asexual development and pathogenesis of Sclerotinia sclerotiorum. Mol. Plant-Microbe Interact. 20:944-954.

Erental, A., Dickman, M. B., and Yarden, O. 2008. Sclerotial development in Sclerotinia sclerotiorum: awakening molecular analysis of a "Dormant" structure. Fungal Biol. Rev. 22:6-16.

Favaron, F., Sella, L., and D'Ovidio, R. 2004. Relationships among endopolygalacturonase, oxalate, $\mathrm{pH}$, and plant polygalacturonase-inhibiting protein (PGIP) in the interaction between Sclerotinia sclerotiorum and soybean. Mol. Plant-Microbe Interact. 17:1402-1409.

Gifford, J. L., Walsh, M. P., and Vogel, H. J. 2007. Structures and metalion-binding properties of the $\mathrm{Ca}^{2+}$-binding helix-loop-helix EF-hand motifs. Biochem. J. 405:199-221.

Godoy, G., Steadman, J. R., Dickman, M. B., and Dam, R. 1990. Use of mutants to demonstrate the role of oxalic acid in pathogenicity of Sclerotinia sclerotiorum on Phaseolus vulgaris. Physiol. Mol. Plant Pathol. 37:179-191.

Gossen, B. D., Rimmer, S. R., and Holley, J. D. 2001. First report of resistance to benomyl fungicide in Sclerotinia sclerotiorum. Plant Dis. 85:1206.

Guimarães, R. L., and Stotz, H. U. 2004. Oxalate production by Sclerotinia sclerotiorum deregulates guard cells during infection. Plant Physiol. 136:3703-3711.

Harel, A., Gorovits, R., and Yarden, O. 2005. Changes in protein kinase a activity accompany sclerotial development in Sclerotinia sclerotiorum. Phytopathology 95:397-404.

Harel, A., Bercovich, S., and Yarden, O. 2006. Calcineurin is required for sclerotial development and pathogenicity of Sclerotinia sclerotiorum in an oxalic acid-independent manner. Mol. Plant-Microbe Interact. 19:682-693.

Huang, L., Buchenauer, H., Han, Q., Zhang, X., and Kang, Z. 2008. Ultrastructural and cytochemical studies on the infection process of Sclerotinia sclerotiorum in oilseed rape. J. Plant Dis. Prot. 115:9-16.

Jamaux, I., Gelie, B., and Lamarque, C. 1995. Early stages of infection of rapeseed petals and leaves by Sclerotinia sclerotiorum. Plant Pathol. 44:22-30.

Jurick, W. M., and Rollins, J. A. 2007. Deletion of the adenylatecyclase ( $s a c 1$ ) gene affects multiple developmental pathways and pathogenicity in Sclerotinia sclerotiorum. Fungal Genet. Biol. 44:521-530.

Kabbage, M., Williams, B., and Dickman, M. B. 2013. Cell death control: the interplay of apoptosis and autophagy in the pathogenicity of Sclerotinia sclerotiorum. PLoS Pathog. 9:e1003287. Published online.

Kelley, L. A., and Sternberg, M. J. E. 2009. Protein structure prediction on the web: a case study using the Phyre server. Nat. Protocols 4:363-371.

Kim, H. J., Chen, C., Kabbage, M., and Dickman, M. B. 2011. Identification and characterization of Sclerotinia sclerotiorum NADPH oxidases. Appl. Environ. Microbiol. 77:7721-7729.

Kim, K. S., Min, J. Y., and Dickman, M. B. 2008. Oxalic acid is an elicitor of plant programmed cell death during Sclerotinia sclerotiorum disease development. Mol. Plant-Microbe Interact. 21:605-612.

Komárek, M., Čadková, E., Chrastný, V., Bordas, F., and Bollinger, J. C. 2010. Contamination of vineyard soils with fungicides: a review of environmental and toxicological aspects. Environ. Int. 36:138-151.

Lewit-Bentley, A., and Réty, S. 2000. EF-hand calcium-binding proteins. Curr. Opin. Struct. Biol. 10:637-643

Li, M., and Rollins, J. A. 2009. The development-specific protein (Ssp1) from Sclerotinia sclerotiorum is encoded by a novel gene expressed exclusively in sclerotium tissues. Mycologia 101:34-43.

Li, M., and Rollins, J. A. 2010. The development-specific ssp1 and ssp2 genes of Sclerotinia sclerotiorum encode lectins with distinct yet compensatory regulation. Fungal Genet. Biol. 47:531-538.

Li, M., Gong, X., Zheng, J., Jiang, D., Fu, Y., and Hou, M. 2005. Transformation of Coniothyrium minitans, a parasite of Sclerotinia sclerotiorum, with Agrobacterium tumefaciens. FEMS (Fed. Eur. Microbiol. Soc.) Microbiol. Lett. 243:323-329.

Li, M., Liang, X., and Rollins, J. A. 2012. Sclerotinia sclerotiorum $\gamma$-Glutamyltranspeptidase $(S s-G g t 1)$ is required for regulating glutathione accumulation and development of sclerotia and compound appressoria. Mol. Plant-Microbe Interact. 25:412-420.

Liberti, D., Rollins, J. A., and Dobinson, K. F. 2013. Peroxysomal carnitine transferase influences host colonization capacity in Sclerotinia 
sclerotiorum. Mol. Plant-Microbe Interact. 26:768-780.

Liu, Y. G., and Chen, Y. 2007. High-efficiency thermal asymmetric interlaced PCR for amplification of unknown flanking sequences. Biotechniques 43:649-665.

Liu, Y., Schiff, M., Marathe, R., and Dinesh-Kumar, S. P. 2002. Tobacco Rar1, EDS1 and NPR1/NIM1 like genes are required for N-mediated resistance to tobacco mosaic virus. Plant J. 30:415-429.

Lumsden, R. D. 1969. Sclerotinia sclerotiorum infection of bean and the production of cellulase. Phytopathology 59:653-657.

Lumsden, R. D., and Dow, R. L. 1973. Histopathology of Sclerotinia sclerotiorum infection of bean. Phytopathology 63:708-715.

Madinger, C. L., Sharma, S. S., Anton, B. P., Fields, L. G., Cushing, M. L., Canovas, J., Taron, C. H., and Benner, J. S. 2009. The effect of carbon source on the secretome of Kluyveromyces lactis. Proteomics 9:47444754.

Magro, P., Marciano, P., and Di Lenna, P. 1984. Oxalic acid production and its role in pathogenesis of Sclerotinia sclerotiorum. FEMS (Fed. Eur. Microbiol. Soc.) Microbiol. Lett. 24:9-12.

Martel, M. B., Letoublon, R., and Fevre, M. 1996. Purification of endopolygalacturonases from Sclerotinia sclerotiorum: multiplicity of the complex enzyme system. Curr. Microbiol. 33:243-248.

Pemberton, C. L., and Salmond, G. P. 2004.The Nep1-like proteins-A growing family of microbial elicitors of plant necrosis. Mol. Plant Pathol. 5:353-359.

Poussereau, N., Gente, S., Rascle, C., Billon-Grand, G., and Fevre, M. 2001. asps encoding an unusual aspartyl protease from Sclerotinia sclerotiorum is expressed during phytopathogenesis. FEMS (Fed. Eur. Microbiol. Soc.) Microbiol. Lett. 194:27-32.

Reddy, V. S., Day, I. S., Thomas, T., and Reddy A. S. N. 2004. KIC, a novel $\mathrm{Ca}^{2+}$ binding protein with one EF-hand motif, interacts with a microtubule motor protein and regulates trichome morphogenesis. Plant Cell 16:185-200.

Riou, C., Freyssinet, G., and Fevre, M. 1991. Production of cell wall degrading enzymes by the phytopathogenic fungus Sclerotinia sclerotiorum. Appl. Environ. Microbiol. 57:1478-1484.

Rollins, J. A. 2003. The Sclerotinia sclerotiorum pac1 gene is required for sclerotial development and virulence. Mol. Plant-Microbe Interact. 16:785-795

Rollins, J. A., and Dickman M. B. 1998. Increase in endogenous and exogenous cyclic AMP levels inhibits sclerotial development in Sclerotinia sclerotiorum. Appl. Environ. Microbiol. 64:2539-2544.

Sambrook, J., and Russell, D. W. 2001. Molecular Cloning: A Laboratory Manual. Cold Spring Harbor Laboratory Press, Cold Spring Harbor, NY, U.S.A.

Sidhu, R. S., Mathewes, S., and Bollon, A. P. 1991. Selection of secretory protein-encoding genes by fusion with PHO5 in Saccharomyces cerevisiae. Gene 107:111-118.

Tamura, K., Peterson, D., Peterson, N., Stecher, G., Nei, M., and Kumar, S. 2011. MEGA5: molecular evolutionary genetics analysis using maxi- mum likelihood, evolutionary distance, and maximum parsimony methods. Mol. Biol. Evol. 28:2731-2739.

Tariq, V. N., and Jeffries, P. 1984. Appressorium formation by Sclerotinia sclerotiorum: scanning electron microscopy. Trans. Br. Mycol. Soc. 82:645-651.

Thompson, J. D., Higgins, D. G., and Gibson, T. J. 1994. CLUSTAL W: improving the sensitivity of progressive multiple sequence alignment through sequence weighting, position specific gap penalties and weight matrix choice. Nucleic Acids Res. 22:4673-4680.

Williams, B., Kabbage, M., Kim, H. J., Britt, R., and Dickman, M. B. 2011. Tipping the balance: Sclerotinia sclerotiorum secreted oxalic acid suppresses host defense by manipulating the host redox environment. PLoS Pathog. 7:e1002107. Published online.

$\mathrm{Xu}, \mathrm{L}$., and Chen, W. 2013. Random T-DNA mutagenesis identifies a $\mathrm{Cu} / \mathrm{Zn}$ superoxide dismutase gene as a virulence factor of Sclerotinia sclerotiorum. Mol. Plant-Microbe Interact. 26:431-441.

Yajima, W., Liang, Y., and Kav, N. N. V. 2009. Gene disruption of an arabinofuranosidase/ $\beta$-xylosidase precursor decreases Sclerotinia sclerotiorum virulence on canola tissue. Mol. Plant-Microbe Interact. 22:783-789.

Yu, Y., Jiang, D., Xie, J., Cheng, J., Li, G., Yi, X., and Fu, Y. 2012. Ss-S12, a novel cell wall protein with PAN modules, is essential for sclerotial development and cellular integrity of Sclerotinia sclerotiorum. PLoS One 7:e34962. Published online.

Zhang, L., Wu, M., Li, G., Jiang, D., and Huang, H. 2010. Effect of mitovirus infection on formation of infection cushions and virulence of Botrytis cinerea. Physiol. Mol. Plant Pathol. 75:71-80.

Zhu, W., Wei, W., Fu, Y., Cheng, J., Xie, J., Li, G., Yi, X., Kang, Z., Dickman, M., and Jiang, D. 2013. A secretory protein of necrotrophic fungus Sclerotinia sclerotiorum that suppresses host resistance. PLoS One 8:e53901. Published online.

Zuppini, A., Navazio, L., Sella, L., Castiglioni, J., Favaron, F., and Mariani, P. 2005. An endopolygalacturonase from Sclerotinia sclerotiorum induces calcium-mediated signaling and programmed cell death in soybean cells. Mol. Plant-Microbe Interact. 18:849-855.

\section{AUTHOR-RECOMMENDED INTERNET RESOURCES}

Broad Institute Sclerotinia sclerotiorum database: www.broadinstitute.org/annotation/genome/sclerotinia_sclerotiorum/ MultiHome.htm

Center for Biological Sequence Analysis (CBS) SignalP server: www.cbs.dtu.dk/services/SignalP

CBS TMHMM server: www.cbs.dtu.dk/services/TMHMM

ExPASy ProtParam tool: web.expasy.org/protparam

ExPASy Scanprosite server: prosite.expasy.org/scanprosite

GenBank database: www.ncbi.nlm.nih.gov/genomes

Phyre2 server:www.sbg.bio.ic.ac.uk/phyre2/html/page.cgi?id=index 